2021-07-27

\title{
Wave, Tide and Topographical Controls on Headland Sand Bypassing
}

King, EV

http://hdl.handle.net/10026.1/17548

10.1029/2020jc017053

Journal of Geophysical Research: Oceans

American Geophysical Union (AGU)

All content in PEARL is protected by copyright law. Author manuscripts are made available in accordance with publisher policies. Please cite only the published version using the details provided on the item record or document. In the absence of an open licence (e.g. Creative Commons), permissions for further reuse of content should be sought from the publisher or author. 
Wave, Tide and Topographical Controls on Headland Sand Bypassing

\author{
E. V. King ${ }^{1,2}$, D. C. Conley ${ }^{1}$, G. Masselink ${ }^{1}$, N. Leonardi ${ }^{3}$, R. J. McCarroll ${ }^{1}$, T. Scott ${ }^{1}$, N. \\ G. Valiente ${ }^{4}$
}

${ }^{1}$ Coastal Processes Research Group, School of Biological and Marine Sciences, Plymouth University, Plymouth, UK.

${ }^{2}$ Scottish Environment Protection Agency, Glasgow, UK.

${ }^{3}$ Department of Geography and Planning, School of Environmental Sciences, University of Liverpool, Liverpool, UK.

${ }^{4}$ Met Office, Fitzroy Road, Exeter, Devon, UK.

Corresponding author: Erin King (erin.king@plymouth.ac.uk)

\title{
Key Points:
}

1. Headland bypassing is potentially widespread on energetic embayed coasts.

2. Bypassing can be predicted for realistic morphology and sand coverage; key parameters are headland extent, surf zone width and toe depth.

3. Tides are a secondary control on bypassing rate under energetic waves. Wave-current interactions can dominate bypassing for median waves.

\section{Key Words:}

Headland bypassing, sediment transport, Delft3D, sediment budget, wave-current interactions, embayed beaches, wave-tide interactions, sediment availability.

This article has been accepted for publication and undergone full peer review but has not been through the copyediting, typesetting, pagination and proofreading process, which may lead to differences between this version and the Version of Record. Please cite this article as doi: 10.1029/2020JC017053.

This article is protected by copyright. All rights reserved. 


\begin{abstract}
Embayed beaches separated by irregular rocky headlands represent $50 \%$ of global shorelines. Quantification of inputs and outflows via headland bypassing is necessary for evaluating long-term coastal change. Bypassing rates are predictable for idealised headland morphologies; however, it remains to test the predictability for realistic morphologies, and to quantify the influence of variable morphology, sediment availability, tides and waves-tide interactions. Here we show that headland bypassing rates can be predicted for wave-dominated conditions, and depend upon headland crossshore length normalised by surf zone width, headland toe depth and spatial sediment coverage. Numerically modelled bypassing rates are quantified for 29 headlands under variable wave, tide and sediment conditions along $75 \mathrm{~km}$ of macrotidal, embayed coast. Bypassing is predominantly wavedriven and nearly ubiquitous under energetic waves. Tidal elevations modulate bypassing rates, with greatest impact at lower wave energies. Tidal currents mainly influence bypassing through wavecurrent interactions, which can dominate bypassing in median wave conditions. Limited sand availability off the headland apex can reduce bypassing by an order of magnitude. Bypassing rates are minimal when cross-shore length $>5$ surf zone widths. Headland toe depth is an important secondary control, moderating wave impacts off the headland apex. Parameterisations were tested against modelled bypassing rates, and new terms are proposed to include headland toe depth and sand coverage. Wave-forced bypassing rates are predicted with mean absolute error of a factor 4.4. This work demonstrates wave-dominated headland bypassing is amenable to parameterisation and highlights the extent to which headland bypassing occurs with implications for embayed coasts worldwide.
\end{abstract}

\title{
Plain Language Summary
}

It is important to understand the inputs and outputs of sand to beaches to effectively predict long term coastal change. This study focuses on the movement of sand between embayed beaches, around headlands, known as headland bypassing. We use a numerical model of a highly energetic $75 \mathrm{~km}$ stretch of coast to predict how much sand moves around the headlands under different wave and tide conditions. We find that bypassing is mostly driven by energetic waves. Changes in water level with the tide has a secondary effect. Tidal currents interact with waves, and this interaction drives bypassing when waves are less energetic. The coverage of sand was also important, with more bypassing if sand is present off the headland toe. The depth of water off the headland apex is an important control on bypassing rate. We test how well a formula to calculate bypassing works, and propose new terms to improve it. This work indicates headland bypassing is potentially ubiquitous along exposed embayed coasts globally.

This article is protected by copyright. All rights reserved. 


\section{Introduction}

Embayed beaches separated by irregular rocky headlands represent around $50 \%$ of the world's shoreline and are important zones ecologically and commercially (Short \& Masselink, 1999). Accurate determination of sediment budgets is necessary for prediction of coastal change over long timescales in these zones. It has been recognised that the traditional view of embayed beaches as closed littoral cells is not accurate for many embayments, where sediment can enter and exit the system via headland bypassing (Goodwin et al., 2013; Ribeiro, 2017; Duarte et al., 2014; Valiente et al., 2019a, b; Vieira da Silva et al., 2016, 2018).

Headland bypassing is defined as the process of sand transport around headlands, which act as obstructions to longshore sediment transport, forced by wave, tide and wind action (Evans, 1943; Valiente et al., 2019a, b; Vieira da Silva et al., 2016, 2018). Headland bypassing can be an important contribution to longshore sediment transport and hence influence coastal sediment budgets and management plans (Thom et al., 2018). Investigations of circulation and bypassing around engineering structures and inlets have been conducted (FitzGerald et al., 2000; Acworth \& Lawson, 2012; Ab Razak et al., 2013; Scott et al., 2016a) whilst more recently studies have focussed on sand bypassing natural headlands (Goodwin et al., 2013; Ribeiro, 2017; Duarte et al., 2014; George et al., 2015; Vieira da Silva et al., 2016, 2018; McCarroll et al., 2018; Valiente et al., 2020; Wishaw et al., 2021). Recent modelling works demonstrate bypassing rates are predictable for individual headlands (McCarroll et al., 2018; Valiente et al., 2020) and idealised headland morphologies (George et al., 2019; McCarroll et al., 2021), however it remains to test this predictability using a range of real headland morphologies, and to examine the influence of embayment morphology, sediment availability, and tidal effects on sand bypassing rates.

Embayment morphology is an important control on embayment circulation, which influences the longshore and cross-shore transport of sediments. Circulation is influenced by embayment length, cross-shore headland extent and surf zone width, incident wave height, incident wave angle, tide state and local bathymetry (e.g. Castelle et al., 2016; McCarroll et al., 2016, 2018; Mouragues et al., 2020; Scott et al., 2016a). Embayment cellular circulation can involve one or two headland attached cellular rip currents, or a single cellular rip current at the centre of the embayment (Castelle et al., 2016). These rips are often referred to as 'mega-rips' (Akan et al., 2020; McCarroll et al., 2016, 2018; Short, 1985), and are associated with high-energy conditions with major storm events thought to be an important driving force of headland-attached rip bypassing (Short \& Masselink, 1999). Embayment length is important in determining the flushing of the surf zone via headland rips with wider embayments allowing greater development of longshore drift in oblique wave conditions, resulting in stronger flushing at the downwave headland (Castelle \& Coco, 2013). Goodwin et al. (2013) observed

This article is protected by copyright. All rights reserved. 
sensitivity of the cross-embayment sand transport pathway downdrift of a headland to the dominant wave direction, and switching between cross-embayment and nearshore transport modes dependent upon incident wave modality and directional power. In addition to the influence of embayment morphology on intra-embayment circulation pathways, it is necessary to consider the influence of headland morphology on the potential for inter-embayment sand transport via headland bypassing.

Headland morphology is an important control on headland bypassing (McCarroll et al., 2019; McCarroll et al., 2021; Wiggins et al., 2019). It is key to quantify headland and embayment morphometric parameters in order to examine their influence on headland bypassing. Such measurements are non-trivial due to the fractal nature of rocky coastlines (Burrough, 1981). Embayment morphometric parameters have been quantified in studies of embayment circulation and rip channel morphology (Short \& Masselink, 1999; Castelle \& Coco, 2012), whilst Fellowes et al. (2019) quantify a range of embayment morphometric parameters and use these to produce a morphometric classification. Recommendations are made in McCarroll et al. (2021) for a method to calculate headland morphometric parameters for use in headland bypassing predictions. George et al. (2015) classify headlands into eight classes based on geomorphic and bathymetric parameters, finding headland perimeter, apex sharpness and bathymetric expression to be most important for controlling headland bypassing under wave forcing. Of these headland classes, it was suggested only one acts as a barrier to sand transport under all conditions, indicating the potential ubiquity of headland sand bypassing. These efforts give a basis from which to derive headland and embayment morphometric parameters for the purpose of predicting headland bypassing rates.

Prediction of headland bypassing has become a recent focus of research on this topic. The classification and method presented by George et al. (2015) can be used to indicate likelihood of headland bypassing and bypassing direction under wave forcing, but does not give an indication of bypassing magnitude. Predictions of bypassing magnitude were initially proposed by McCarroll et al. (2018), where a headland-specific parameter was conceived based upon modelled daily sand bypassing of a macrotidal headland. George et al. (2019) found that bypassing is controlled by wave angle, headland size and grain size. Valiente et al. (2020) show that headland bypassing of multiple headlands is predictable as a function of offshore wave power, although this requires a computationally expensive numerical model to first calibrate a polynomial to each headland. By modelling headland bypassing of a large number of synthetic headlands, McCarroll et al. (2021) demonstrated that headland bypassing $Q_{b}$ can be parameterised as an initial approximation as a function of headland cross-shore extent $X_{\text {head }}$ and surf zone width $X_{\text {surf: }}$

This article is protected by copyright. All rights reserved. 


$$
Q_{b_{-} \text {orig }}=Q_{0} \cdot e^{-\left(\frac{X_{\text {head }}}{X_{\text {surf }}}\right)^{2}},
$$

Where the unconstrained open coast longshore sediment flux $Q_{0}$ is estimated using van Rijn (2014):

$$
Q_{0}=0.00018 \cdot K \cdot g^{0.5} \cdot \tan (\beta)^{0.4} \cdot D_{50}^{-0.6} \cdot H_{s, b}^{3.1} \cdot \sin \left(2 \alpha_{b}\right),
$$

In which $K$ is a proxy for wave period where $K$ is 1.5 for swell waves and 1 for wind waves, $g$ is gravitational acceleration, $\tan (B)$ is beach slope, $D_{50}$ is median grain size, $H_{s, b}$ is breaking wave height and $\alpha_{b}$ is breaking wave angle relative to shore-normal. This parameterisation has the benefit of being calculable without use of computationally expensive numerical techniques. However, there are important limitations to be addressed to support application of this parameterisation to embayed coasts in realistic settings.

It remains to test the current headland bypassing parameterisation of McCarroll et al. (2021) on a range of realistic headland morphologies. As opposed to idealised scenarios, circulation and bypassing can be influenced by embayment morphology and nearby headlands, sediment availability off the headland toe, and headland underwater bathymetric expression (George et al., 2015, 2019; McCarroll et al., 2018, 2021; Scott et al., 2016a; Wishaw et al., 2021). The influences of bathymetric expression and sediment spatial variability in sand bypassing rates are yet to be quantified. Additionally, while waves are the primary driver of headland sand bypassing based on observation and modelling studies (Goodwin et al., 2013; Vieira da Silva et al., 2018; McCarroll et al., 2018; George et al., 2019), tidal elevations and tidal currents play a secondary role (McCarroll et al., 2018, 2021). Costa et al. (2019) indicate non-linear interaction between waves and tides can increase bypassing by an order of magnitude relative to tides-alone. A recent review of the major controls on headland bypassing is given by Klein et al. (2020). Uncertainty remains as to the influence of these variables and how they relate to headland bypassing in a manner which could be included in bypassing parameterisations, which we aim to address in this study.

This paper aims to test the applicability of existing headland bypassing parameterisations against realistic headland morphologies, and to expand the parameterisations to include the influence of headland underwater expression, sediment availability and embayment morphology. We also aim to quantify the impact of tides and non-linear wave-tide interactions on headland bypassing rates. The North Coast of Cornwall presents ideal conditions for this investigation, with a wide variety of embayed beaches separated by irregular and varied rocky headlands, energetic waves, spatially variable sand coverage and macrotidal regime (King et al., 2019). We quantify headland and embayment morphologies and sediment spatial variability across this region and determine sand bypassing rates under various physical forcing conditions using a validated coupled hydrodynamic,

This article is protected by copyright. All rights reserved. 
wave and sediment transport model. The following objectives are addressed: (i) testing the performance of the parameterisation as presented in McCarroll et al. (2021) against realistic headland morphologies, and suggesting improvements; and (ii) examining the impact of tidal currents and wavecurrent interactions on headland bypassing relative to wave-only forcing.

\section{Study Area}

The North Coast of Cornwall is situated in the South West United Kingdom, on the Northwest European Continental Shelf (Figure 1). Resonant effects contribute to large tidal amplitudes over the whole Celtic shelf, with a mean spring tide range (MSTR) in the study area of circa $5 \mathrm{~m}$ in the Southwest and increasing to $>7 \mathrm{~m}$ at Hartland Point (Uncles, 2010). Modelled regional scale bed shear stresses, tidal residual currents and sand transport pathways indicate residual sand transport towards the northeast along this coastline, progressively weakening as it moves up coast (Pingree \& Griffiths, 1979; Holt et al., 2001; Uncles, 2010; King et al., 2019). Strong tidal currents (around $1.5 \mathrm{~ms}^{-1}$ at springs) drive a net residual current of up to $15 \mathrm{cms}^{-1}$ towards the northeast immediately adjacent to large coastal promontories. This residual is broken up by multiple headland-bound embayments, resulting in areas of low residual tidal transport close to shore. In combined wave and tide conditions, sand transport is wave dominated for median waves in these areas where tidal forcing is weakest and is wave dominated across the whole North Coast under extreme waves (King et al., 2019).

A 75-km stretch of this coast was selected for this study (Figure 1). This section of coastline is comprised of embayed beaches separated by irregular rocky headlands (29 embayments were selected for this study). Beaches in the study area are comprised of medium quartz sand (Prodger et al., 2016). These embayments comprise a wide range of wave exposures, embayment lengths, degrees of embaymentisation and headland morphologies. This coast is directly exposed to the Atlantic, bringing waves with potential fetch lengths of $6000 \mathrm{~km}$ (Collins, 1987). Winter storm $H_{s}$ at nearshore wave buoys along the North Coast can exceed $6 \mathrm{~m}$ (Scott et al., 2016b). Average $H_{s}$ based on a 10-year hindcast of WAM is $\sim 1.5 \mathrm{~m}$ along this section of coast, with $H_{s}$ of $\sim 2 \mathrm{~m}$ further offshore (Bricheno et al., 2015; King et al., 2019). The wave climate in the region has experienced an increase in extreme (99th percentile) $H_{s}$ of up to $1 \%$ per annum between 1985 and 2008, and has also experienced an increase in winter wave height and interannual variability (Young et al., 2011; Castelle et al., 2018).

The large tidal range, high degree of wave exposure and diversity of headland and embayment morphologies make this a suitable site for an investigation into the impacts of different environmental and morphological forcing conditions on potential headland bypassing.

This article is protected by copyright. All rights reserved. 


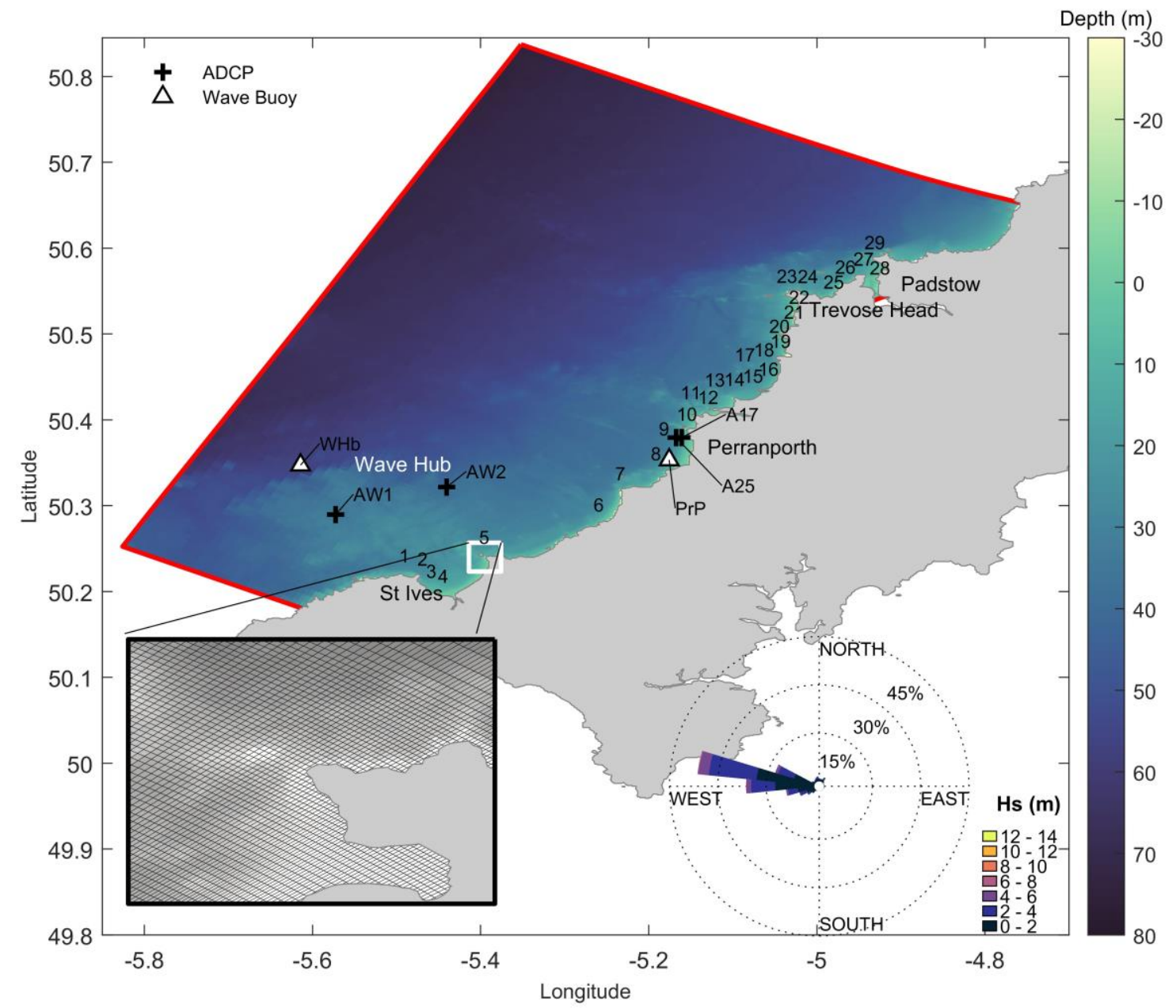
1. Clodgy Point
2. St Ives Head
3. Porthminster Point
4. Carrack Gladden
5. Godrevy Point
6. Porthtowan South
7. St Agnes Head
8. Cligga Head
9. Ligger Point
10. Penhale Point
11. Kelsey Head
12. Pentire Point West
13. Pentire Point East
14. Towan Head
15. Porth South

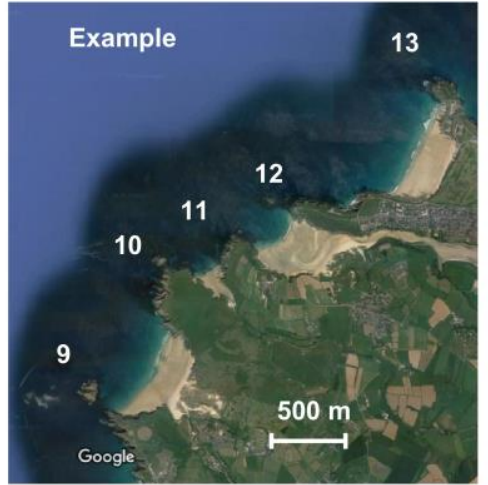

Figure 1: Map of the North Coast of Cornwall as represented within the model domain, showing the wave computational grid and bathymetry. The inset around Godrevy Point shows the computational grid as an example of the localised grid refinement around headlands. Headlands are numbered from southwest to northeast as indicated, and their names are included below the map. Other locations of reference are annotated. ADCP deployments $(+)$ and wave buoy locations $(\Delta)$ are marked, alongside their name as referred to in the text. Open model boundaries are marked with a solid red line. A wave rose of the wave climate at the Wave Hub between 01-June-2015 and 31-May-2018 is inset bottom-right, showing principle wave directions. An example aerial image of headlands $9-13$ is included for reference (bottom right). For the purpose of this study, upcoast is defined as towards the northeast (increasing headland number).

This article is protected by copyright. All rights reserved. 


\section{Methods}

\subsection{Numerical model}

The process-based numerical model Delft 3D was used to model the North Coast (Figure 1). The FLOW hydrodynamic module was 2-way coupled to a SWAN third-generation spectral wave model packaged as Delft3D WAVE with an identical grid. Three-dimensional hydrodynamics are calculated using the unsteady shallow-water equations, following the Boussinesq approximation with the vertical momentum equation reduced to the hydrostatic pressure relation, assuming that vertical accelerations are small relative to gravitational acceleration (Lesser et al., 2004). The contribution of 3D turbulent eddies is modelled using a $k-\varepsilon$ turbulence model. SWAN, packaged as Delft3D-WAVE, is a third-generation phase-averaged wave model based on fully spectral representation of the action balance equation, accounting for wave-current interaction through radiation stress, refraction, wind generation, whitecapping, nonlinear wave-wave interactions, bottom dissipation, and depth-induced breaking (Booij et al., 1999).

The North Coast model was one-way nested within a regional fully coupled hydrodynamic, wave and sand transport model validated and presented in King et al. (2019). Grid resolution of the North Coast model was circa $50 \mathrm{~m}$ in the vicinity of headlands, and the model was run in 3D hydrodynamic mode with 10 sigma-levels in the vertical. The WAVE grid was extended two grid cells out from the FLOW grid. Bathymetry was derived from merged high-resolution multibeam data from the UK Hydrographic Office and lidar data Plymouth Coastal Observatory, corrected to Mean Sea Level 2000 datum using the Vertical Offshore Reference Frame (Turner et al., 2010) and merged with coarser EMODnet bathymetry offshore (EMODnet Bathymetry Consortium, 2016; Figure 1). Bathymetry at the boundaries matched the bathymetry of the regional forcing model. High-resolution bathymetry was assigned to the grid using spatial averaging, while lower resolution EMODnet bathymetry was assigned to the grid using triangular interpolation.

The hydrodynamic model has two water level boundaries and one velocity boundary to the southwest. This combination of forcing types provided the best agreement with observations during calibration. Boundaries were situated far from the headlands of interest. Boundary conditions were linearly interpolated from the regional model, which was itself one-way nested within the Atlantic Margin Model (FOAM-AMM7; McConnell et al., 2017; O'Dea et al., 2012). The hydrodynamic timestep was $12 \mathrm{~s}$. Wind fields were interpolated linearly from $0.25^{\circ}$ resolution scatterometer blended 6hourly mean wind fields retrieved from the Copernicus Marine Service (Bentamy \& Fillon, 2012). Atmospheric pressure was interpolated linearly to the model grid from the $0.5^{\circ}$ resolution Climate Forecast System version 2 model (Saha et al., 2014).

This article is protected by copyright. All rights reserved. 
The wave model was forced with parametric boundary conditions $\left(H_{s}, T_{p}\right.$, direction, directional spreading) linearly interpolated from the regional model at $1 \mathrm{~km}$ resolution at the open boundaries. For calibration and validation the regional model in turn was forced by the UK Met Office Wave Watch III continental shelf model (King et al., 2019; Saulter, 2017). The wave model was simulated in nonstationary mode, with a time-step of 10 minutes, and a coupling interval between WAVE and FLOW of 1 hour, where wave forces are passed based on energy dissipation rate radiation stresses, bed shear stresses, Stokes drift and bottom orbital velocity, and receiving water levels and velocities. The wave model had a directional resolution of $5^{\circ}$ ( 72 bins over a full circle) and 24 frequency bins between 0.05 and $1 \mathrm{~Hz}$.

Numerical model calibration was performed using ADCP data at the Wave Hub, and wave buoy data at Perranporth (AW1/2 \& PrP; Figure 1) over a 32-day window between 23/12/2013 and 24/01/2014, including three large storm events. The Manning bottom friction formulation with a uniform roughness coefficient of 0.0275 performed best, as well as the Fredsøe (1984) bed shear stress formulation. Waves were calibrated for whitecapping formulations, bed friction formulations and bed friction coefficients. Calibration of these had a significant impact on wave model skill, with the default combination overestimating $H_{s}$ at Perranporth. The best performing combination was the formulation of Komen et al. (1984) for whitecapping, Madsen et al. (1988) for bed friction, with a bed friction coefficient of 0.05. A full list of model formulations and parameters is included in Appendix A. Model validation was performed over a separate energetic epoch, and validation results are presented in Section 4.1.

\subsection{Sediments}

Simulations were conducted under two bed composition scenarios: (i) a spatially uniform sediment coverage, to enable comparison of bypassing rates between different headlands; and (ii) a realistic sediment spatial coverage to highlight the role of sediment spatial availability on bypassing.

A uniform grain size of $330 \mu \mathrm{m}$ (Prodger et al., 2017) was used throughout the domain, allowing crosscomparison of different embayments. Whilst this enables isolation of the controls of headland morphology on bypassing rates, it means absolute bypassing rates reported here will likely be underestimated in embayments with finer sediments, such as Padstow to the northeast (Figure 1; Prodger et al., 2016; Oyedotun, 2020). The influence of different grain sizes on bypassing around an individual headland is covered by McCarroll et al., (2021; see also George et al., 2019; Klein et al., 2020). In the parameterisation of headland bypassing (equation 1; McCarroll et al., 2021), grain size is an input to the calculation of unconstrained longshore flux (equation 2; van Rijn, 2014). Modelled sand transport rates were calculated using the TRANSPOR2004 formulation of van Rijn (2007a, b; see also

This article is protected by copyright. All rights reserved. 
van Rijn et al., 2004). The TRANSPOR2004 sediment transport formulation computes sediment transport contributions of suspended and bed load transport for both currents and waves, including their interactions. Enhancement of bed shear stress under currents and waves is accounted for in Delft3D following the method of Soulsby et al. (1993).

\subsubsection{Spatially variable sediment coverage}

To model the influence of spatial variability in sand coverage it is necessary to determine what locations in the domain are covered with sand or are exposed rock or gravel. Maps of spatial sediment classes available in the region such as the British Geological Survey product DiGBS250K are coarse, and unsuitable for modelling at the resolution required by this study. Consequently, an alternative method to determine sediment spatial variability was developed. High-resolution $(2 \mathrm{~m})$ UKHO bathymetry was used for this purpose. These data cover all embayments in this study. The bathymetry was resampled to $10 \mathrm{~m}$ resolution for reasons of computational efficiency (Figure 2a). A 100m median filter was applied to generate a smoothed surface. This surface was subtracted from the resampled bathymetry (Figure $2 \mathrm{~b}$ ). The standard deviation of this surface was calculated over the same $100 \mathrm{~m}$ square window, and the maximum of this standard deviation was calculated over this window (Figure 2c). This highlighted regions of rock across the domain. Polygonal areas of sediment in each embayment were then selected by eye roughly following the $0.2 \mathrm{~m}$ threshold (Figure $2 \mathrm{~d}$ ).

This method assumes areas of sediment are vertically smoother than rock over a $100 \mathrm{~m}$ window. Some sediment features were highlighted as rock due to their large vertical expression (such as large sandwaves west of St Ives). These were identifiable due to their linear, repeating pattern, and included in the sediment polygons. Perranporth has a sand-gravel transition at circa -26m ODN (Valiente et al., 2019a). This was identifiable in the data as a border with elevated maximum standard deviation and was used to define to offshore sand polygon boundary. Similar borders elsewhere were also used for this purpose. The purpose of this was not to determine the exact spatial extent of sediment across this region, as this would require a more detailed observational campaign to determine sediment physical characteristics and spatial extent. Rather, the method was used as a means of generating an approximate sediment coverage to test the effect of a realistic pattern of sediment spatial coverage on headland bypassing rates versus a uniform, homogeneous sand bed. As such, this method was considered sufficient for the purpose of this study.

This article is protected by copyright. All rights reserved. 

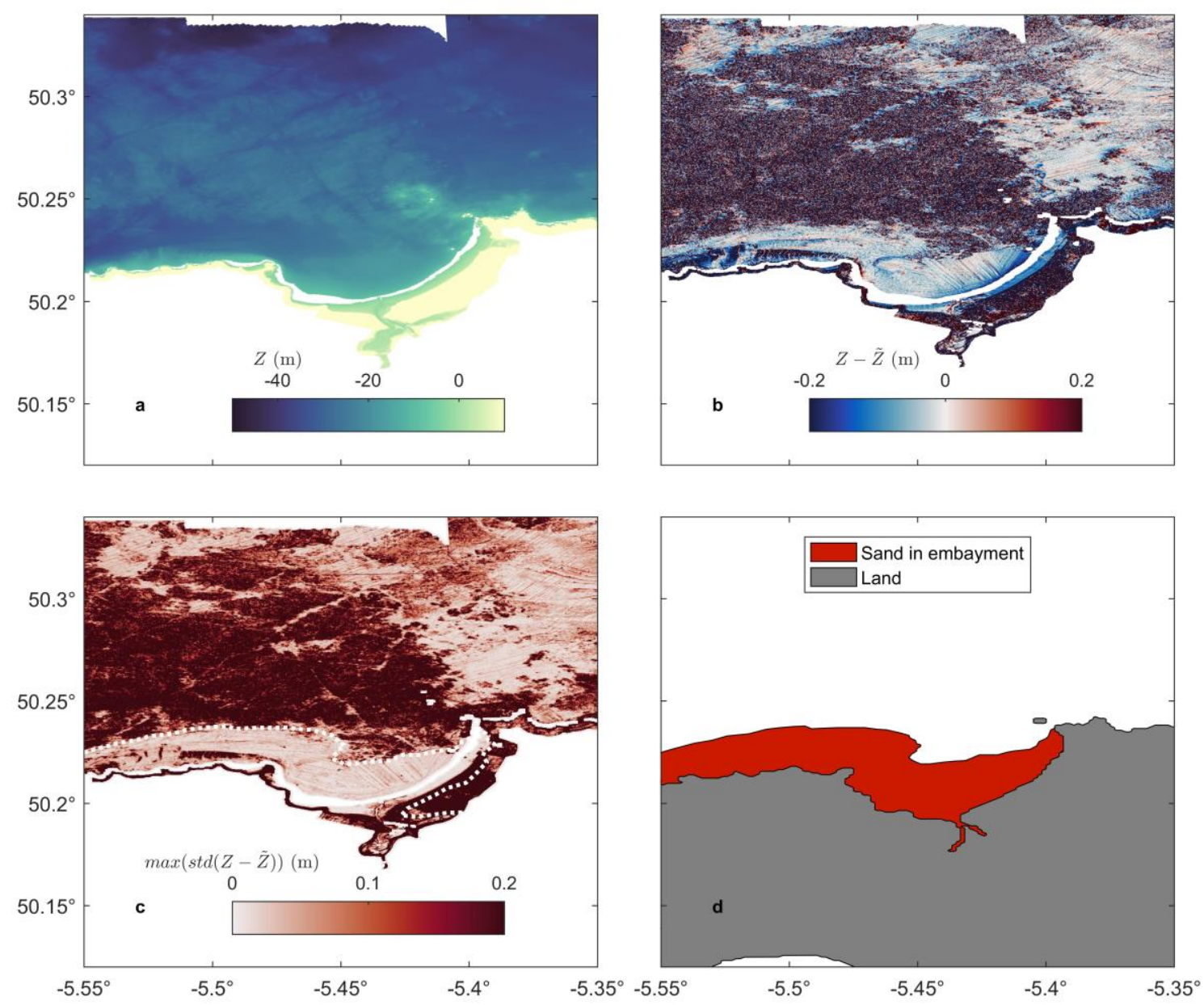

Figure 2: Sediment availability determination: example from St Ives Bay. (a) 10m resampled UKHO bathymetry. (b) The difference surface once a 100m window median filtered surface was subtracted from (a). (c) Maximum standard deviation of (b) over the same 100m window. Areas of high vertical variability are assumed to generally correspond to rock offshore. The selected sand-rock boundary is indicated with a white dashed line, corresponding to roughly the $0.2 \mathrm{~m}$ contour offshore. (d) Polygons of spatial sand extent in embayments of interest, determined by eye from (c), also indicating areas of land.

\subsection{Simulated scenarios}

The wave climate was characterised near the offshore boundary using wave buoy data from the Wave Hub (Figure 1) over three years from 01-June-2015 to 31-May-2018. A Gumbel copula was fitted to the data for $H_{s}$ and $T_{p}$ to describe the joint probability distribution with $H_{s}$ and $T_{p}$ represented by gamma and rician marginal distributions respectively, following the method described in Genest \& Favre (2007; Figure 3). Marginal distributions were selected based on optimal performance minimising the Akaike Information Criterion. Joint $H_{s} \cap T_{p}$ conditions were selected from this distribution for exceedance probabilities of .50, .05 and.0014, the latter representing 12-hour exceedance. These predicted exceedances are in agreement with values for the region presented in the literature

This article is protected by copyright. All rights reserved. 
(Bricheno et al., 2015; King et al., 2019; Scott et al., 2016b). Three modal wave directions were selected (Figure 3). Peak orbital velocities in the region are induced by swell wave action (Draper, 1967) and, consequently, scenarios presented here beyond calibration and validation exclude wind forcing.

Wave-only, tide-only and coupled wave-tide scenarios were conducted. Wave-only scenarios were conducted for two water levels $( \pm 3.5 \mathrm{~m}$ ) corresponding approximately to spring high water (SHW) and spring low water (SLW) to give maximum variability in tidal elevations tested. Tidal scenarios were conducted over a spring-neap cycle and times where water levels were at Spring High or Spring Low were extracted for analysis. Velocities at these times ranged from $0.02-1 \mathrm{~ms}^{-1}$. All scenarios were simulated for a uniform homogeneous sand bed and for the spatially variable sand coverage demonstrated in Figure 2. This resulted in a total of 56 scenarios for analysis.

Sand transport components were rotated to their along-shore and cross-shore components along each apex transect (Figure5) and these components were integrated from the headland apex to the maximum depth of transport (DoT; Valiente et al., 2019a) as a measure of instantaneous headland bypassing rate $Q_{b}\left(\mathrm{~m}^{3} \mathrm{~s}^{-1}\right)$. Headlands have both an up-coast and down-coast transect defined by the beach orientation adjacent to each side of the headland (see Section 3.5). Bypassing was defined as positive up-coast (generally towards the northeast). Where bypassing rates at the two transects were divergent, bypassing was set to zero. There were no cases of convergent transport in the modelled bypassing rates. Sand transport rates lower than the range of validation presented in van Rijn (2007b) were set to zero prior to integration $\left(0.00016 \mathrm{~m}^{3} / \mathrm{m} /\right.$ tidal cycle).

Wave-only scenarios were run for 72 hours, and sand transport was averaged over the final 24 hours. In tidal scenarios, times of spring high and low water were defined as when the median water level across each transect was $>+3 m$ or $<-3 m$ relative to mean sea level (MSL2000 datum) respectively. Tide range increases towards the northeast; therefore, the number of points satisfying this criteria increased from 12 to 17 moving up-coast. This absolute criteria was chosen over a normalised criteria to allow comparability of bypassing rates in the tidal scenarios with the wave-only scenarios where water levels were fixed at $\pm 3.5 \mathrm{~m}$. Bypassing rates were averaged over all times where the water level was within the SHW or SLW depth bin at each headland.

This article is protected by copyright. All rights reserved. 

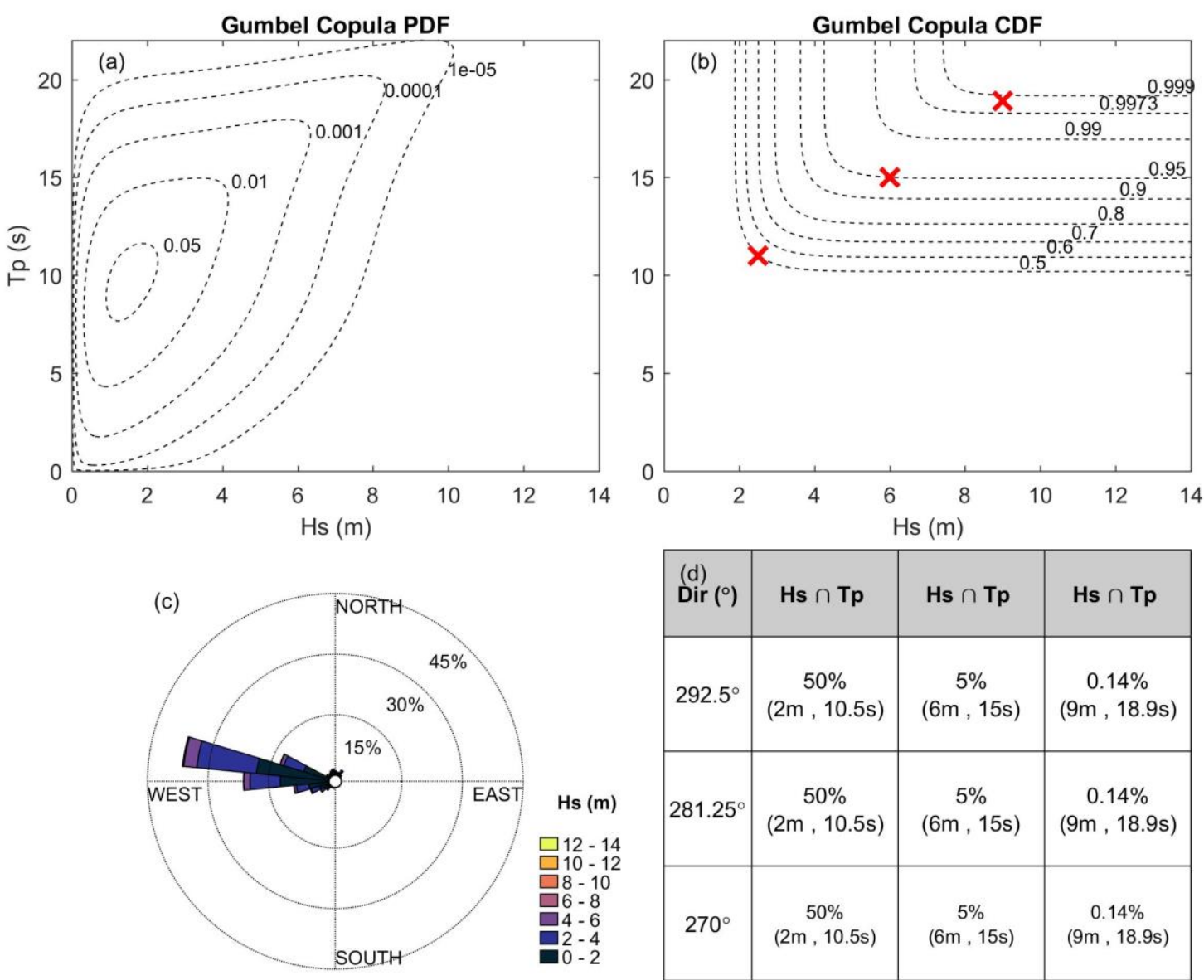

\begin{tabular}{|l|c|c|c|}
\hline $\begin{array}{l}(\mathrm{d}) \\
\text { Dir }\end{array}\left(^{\circ}\right)$ & Hs $\cap$ Tp & Hs $\cap \mathbf{T p}$ & Hs $\cap \mathbf{T p}$ \\
\hline $292.5^{\circ}$ & $\begin{array}{c}50 \% \\
(2 \mathrm{~m}, 10.5 \mathrm{~s})\end{array}$ & $\begin{array}{c}5 \% \\
(6 \mathrm{~m}, 15 \mathrm{~s})\end{array}$ & $\begin{array}{c}0.14 \% \\
(9 \mathrm{~m}, 18.9 \mathrm{~s})\end{array}$ \\
\hline $281.25^{\circ}$ & $\begin{array}{c}50 \% \\
(2 \mathrm{~m}, 10.5 \mathrm{~s})\end{array}$ & $\begin{array}{c}5 \% \\
(6 \mathrm{~m}, 15 \mathrm{~s})\end{array}$ & $\begin{array}{c}0.14 \% \\
(9 \mathrm{~m}, 18.9 \mathrm{~s})\end{array}$ \\
\hline $270^{\circ}$ & $\begin{array}{c}50 \% \\
(2 \mathrm{~m}, 10.5 \mathrm{~s})\end{array}$ & $\begin{array}{c}5 \% \\
(6 \mathrm{~m}, 15 \mathrm{~s})\end{array}$ & $\begin{array}{c}0.14 \% \\
(9 \mathrm{~m}, 18.9 \mathrm{~s})\end{array}$ \\
\hline
\end{tabular}

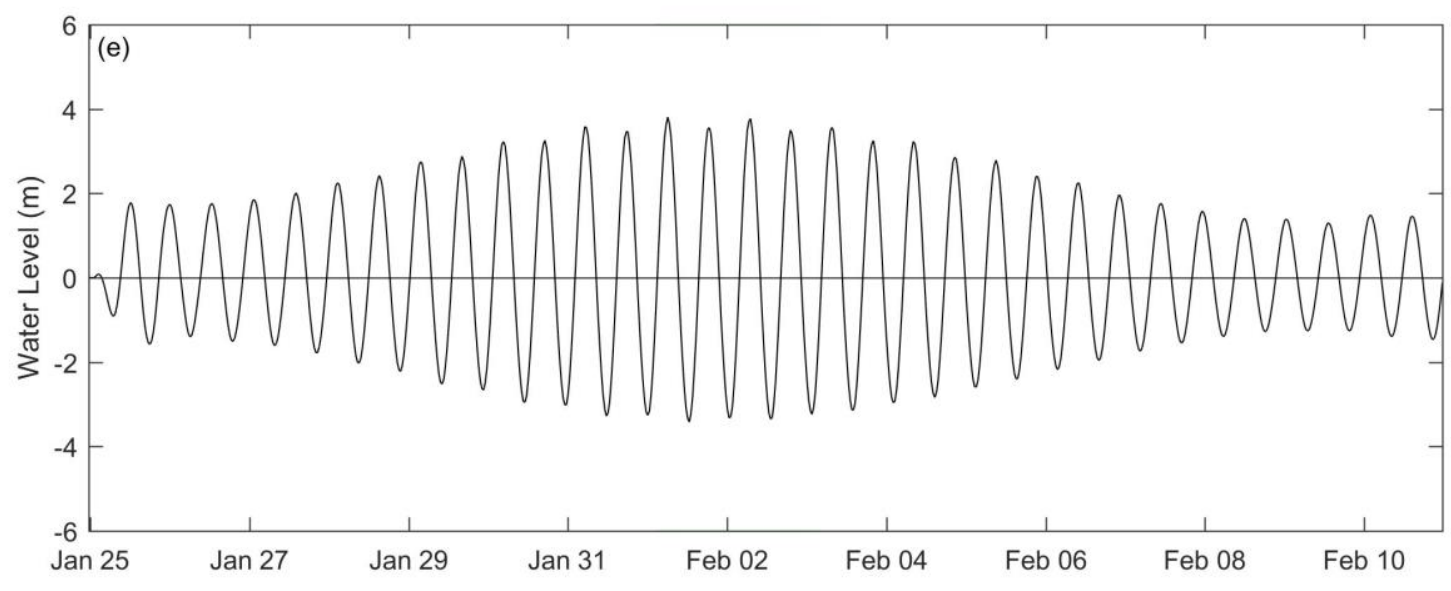

Figure 3: Wave climate characterisation used to select conditions for simulation. (a) Gumbel copula PDF representing the joint probability density of $H_{s}$ and $T_{p}$. (b) Gumbel copula CDF representing the cumulative joint probability of $H_{s}$ and $T_{p}$ from which conditions were selected (red crosses). (c) Wave rose showing three modal wave directions from West to West-northwest. (d) Wave conditions selected for simulations. (e) Example tidal signal from Perranporth during the tide-only simulation. The first 7 days were used as model spin-up.

This article is protected by copyright. All rights reserved. 


\subsection{Quantifying morphometric and environmental parameters}

Headland and embayment morphometric and environmental parameters were selected for their relevance to existing headland bypassing parameterisation efforts (McCarroll et al., 2019; 2021), or for exploratory purposes. Parameters relevant to the calculation of uninhibited longshore transport (van Rijn, 2014; Equation 2) and the blocking potential of a headland (McCarroll et al., 2021; Equation 1) described in this section include headland cross-shore length $X_{\text {head }}$, surf zone width $X_{\text {surf, }}$ breaking wave height $H_{s, b}$, breaking wave angle relative to shore-normal $\alpha_{b}$ and beach slope 6 . Exploratory morphometric parameters include headland toe depth $Z_{\text {toe }}$ and beach length $L_{b}$. Parameters related to spatially variable sediment coverage were explored, including the relative coverage of sediment adjacent to the headland $R_{\text {sed }}$ and the cross-shore extent of sediment coverage $X_{\text {sed }}$.

In this study, morphometric parameters were calculated using bathymetry as interpolated to the model grid, to ensure relation to the bathymetry used by the model in the calculation of model hydrodynamics, wave propagation and sand transport. Headland morphology is measured in relation to the waterline around the headland for the water level under consideration, resulting in an apparent morphology that varies over a tidal cycle. Morphology of the headland is considered on the up-wave side, between the beach and the headland apex, defined as the furthest point of the headland crossshore perpendicular to the water line on the beach. Thus, headland morphology down-wave of the apex is not considered as sediment is considered to have bypassed the headland once past the headland apex in this study, and hence only the up-drift headland aspect influences the instantaneous bypassing potential as parameterised here (McCarroll et al., 2021). Headland and embayment morphometric parameters used are depicted in Figure 4.

The apparent headland cross-shore extent $X_{\text {head }}$ for a certain water level is measured perpendicular to the orientation of the waterline on the up-wave beach adjacent to the headland (McCarroll et al., 2021; Figure 4b). For very small beach lengths, where determination of the beach orientation at the resolution of the model was subject to greatest error, the orientation was determined from either the adjacent bay or the general orientation of that stretch of coastline.

Depth off the headland toe $Z_{\text {toe }}$ was determined $50 \mathrm{~m}$ offshore of the headland apex along the apex transect (Figure $4 \mathrm{~b}$ ). The point $50 \mathrm{~m}$ offshore relates to model resolution which aimed to be $\lesssim 50 \mathrm{~m}$ around the headlands. Therefore, this point was chosen as the first wet grid node off the headland apex. This was nondimensionalised across all headlands by dividing by $50 \mathrm{~m}$ to give the slope of the headland toe $m_{t}$ :

$$
m_{t}=\frac{Z_{t o e}}{50 m}
$$

This article is protected by copyright. All rights reserved. 
Beach length $L_{b}$ was calculated between the two headland faces using the point of intersection between the headland face and the beach (Fellowes et al., 2019), defined at the point where the water level contour diverges offshore from the general orientation beach (Figure 4b).

Surf zone width $X_{\text {surf }}$ is measured perpendicular to the beach waterline adjacent to the headland (Figure 4c), from the beach waterline to the edge of the outer surf zone. For the purpose of this study, this was defined as the point at which the fraction of wave energy dissipation due to breaking reached $5 \%$. This was derived from the model. Breaking wave height $H_{s, b}$ and direction at breaking $\alpha_{\mathrm{b}}$ were then interpolated from the model at this point. Beach slope was also determined along this transect from the waterline to the DoT, taken from Valiente et al. (2019a).

Sediment coverage was considered between the headland adjacent transect and the headland apex transect (Figure $4 \mathrm{~d}$ ). This adjacent transect was positioned at $100 \mathrm{~m}$ from the headland intersection with the beach, or at the midpoint of the beach if $L_{b}<200 \mathrm{~m}$. Exploratory parameters included the cross-shore sediment extent $X_{\text {sed }}$ and the area of sediment coverage adjacent to the headland $A_{\text {sed. }}$. This was used to determine the ratio $R_{\text {sed }}$ defined as:

$$
R_{\text {sed }}=\frac{A_{\text {sed }}}{A_{D o T}},
$$

Where $A_{D o t}$ is the total area between the adjacent and apex transects, bounded by the headland face and DoT.

This article is protected by copyright. All rights reserved. 

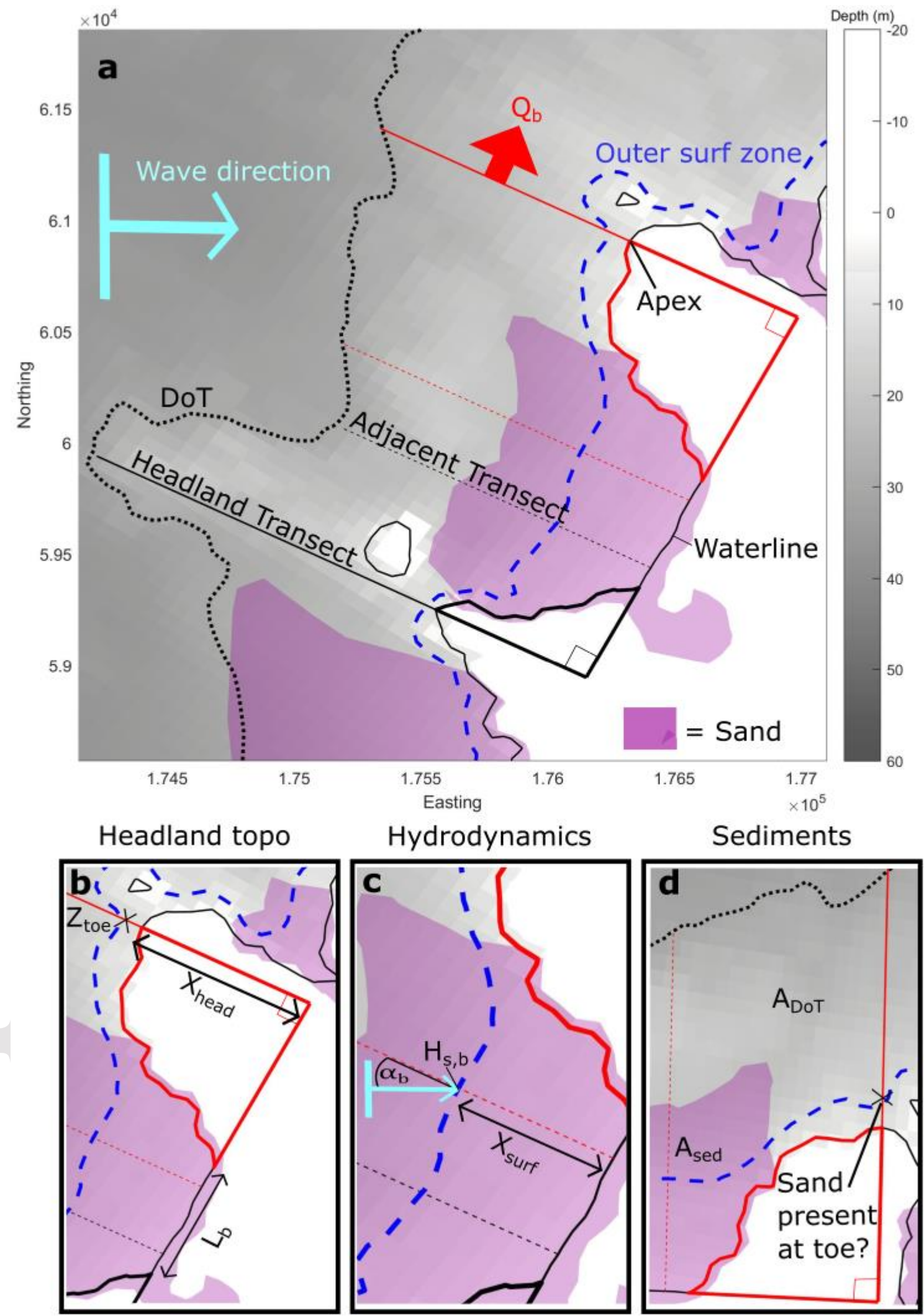

Hydrodynamics

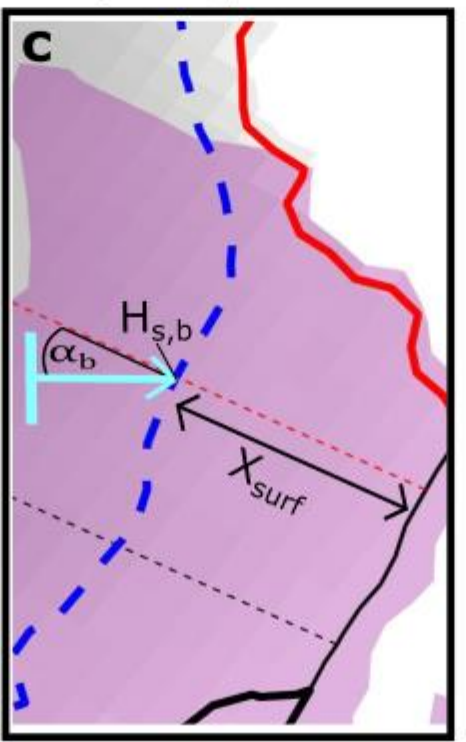

Sediments

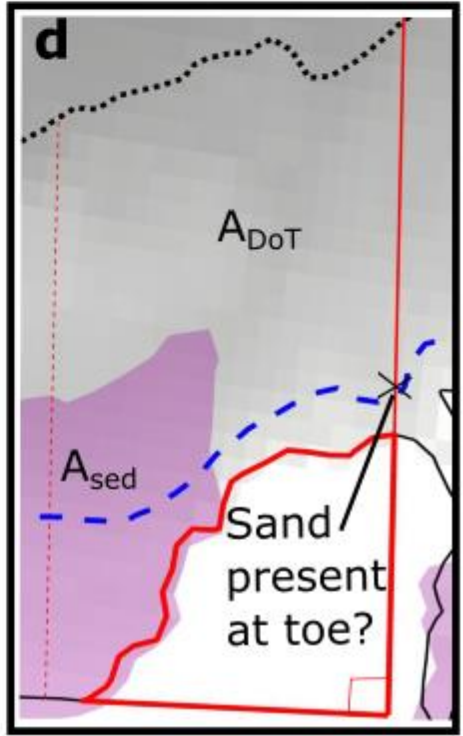

Figure 4: Example schematic of morphological and environmental parameters at Holywell Bay at spring high water. (a) Schematisation of the embayment with headland apex transects (solid line) and adjacent beach transects (dashed line) coloured by their respective headland. Other features shown include incident wave direction (light-blue arrow), maximum Depth of Transport (thick black dotted line), outer surf zone (blue dashed line), sand cover (purple shading), and sand bypassing

This article is protected by copyright. All rights reserved. 
rate $Q_{b}$ (red arrow). (b) Headland topographical parameters including cross-shore headland length $X_{\text {head }}$, beach length $L_{b}$, and headland toe depth $Z_{\text {toe. }}$ (c) Hydrodynamic parameters including breaking wave angle $\alpha_{b}$ relative to shore normal, breaking wave height $H_{s, b}$, and surf zone width $X_{\text {surf. }}$ (d) Sediment parameters including sand coverage area adjacent to headland $A_{\text {sed }}$, total area between headland and maximum depth of transport $A_{D o T}$, and "is sediment present at the headland toe?" In all subplots, bathymetry is indicated in grayscale where sediment is not present.

\section{Results}

\subsection{Validation}

Validation of the model was performed for waves using wave buoys at Perranporth and Wave Hub, and for currents using ADCP derived currents offshore of the North headland of Perranporth (Figure 5; For locations, see Figure 1). Validation was performed over a 92-day period from 2016/06/01 to 2016/09/01 including an energetic event of $20^{\text {th }}$ August. Time series in Figure 5 show a subset of the validation period for clarity. The tidal current axis is predominantly north-south oriented at the deployment sites, with very low east-west velocity components; therefore, only northward velocity components are shown in Figure 5. East-west components are validated and their skill metrics shown in Table 1.

Scatter plots in Figure 5 show all 2016 comparison data from which model skill was determined. Validation skill metrics are shown in Table 1. Skill was assessed using the following metrics: $R^{2}, B I A S$, mean absolute error MAE, Willmott Index of Agreement WIA and Brier Skill Score BSS. Equations for these metrics are included in Appendix B. Values of $B S S \geq 0.8$ were considered excellent, $\geq 0.6$ considered good, $\geq 0.3$ considered reasonable, and $<0.3$ considered poor.

Validation of velocity components was performed for both the depth-integrated and near-bed velocities to assess model skill through the water column (relevant to suspended load transport) and near the bed (relevant to bed shear stress and sediment resuspension). In general, the model has good or excellent skill for both depth-integrated and near-bed instantaneous and residual (low-pass filtered) northward velocity components. The lowest performing residual northward velocity skill is the near-bed velocity at A17, which has "reasonable" skill. Eastward velocity components at both $A D C P$ deployments were very small, which resulted in lower Brier Skill and $R^{2}$ metrics. A more informative metric at these sites is WIA: with $-0.09 \leq$ WIA $\leq 0.56$ indicating the sum of the model error magnitudes is roughly equal to or less than the sum of the observed variability in the ADCP data, by half for a value of 0.5 . The $M A E$ for all velocity comparisons does not exceed $5 \mathrm{cms}^{-1}$.

The model has excellent skill for $H_{s}$ and good skill for $T_{p}$. There is a slight northward bias in wave direction ( $\sim 7^{\circ}$ across all observations, increasing to $\sim 14^{\circ}$ at the Perranporth buoy). The influence of

This article is protected by copyright. All rights reserved. 
this bias is likely to vary by embayment and depend upon multiple factors, including headland orientation, beach orientation adjacent to the headland, the general orientation of the coastline, and proximity and topography of adjacent embayments and headlands which can influence circulation patterns (McCarroll et al., 2018). As this study focuses on parameterisation of modelled bypassing rates, the exact replication of wave directions is secondary to quantification of the influence of variable wave climate on headland bypassing rates. Nonetheless, comparisons between predicted bypassing patterns presented in Section 4.3 and observed morphological changes over an energetic winter period (Burvingt et al., 2017) indicate agreement with observations for this coastline (see Section 5.2/ Text S2 \& Figure S12 in the supporting information). The positive WIA for wave direction indicates modelled errors are within the magnitude of observed variability about the mean direction $(0.07 \leq W I A \leq 0.35)$.

Validation of sand transport rates is impossible due to a lack of observation data. McCarroll et al. (2018) applied sediment transport settings from the literature to model headland sand-bypassing at Perranporth (Figure 1). King et al. (2019) used observed bedform asymmetry in high resolution bathymetric survey data and sand transport rates reported in the literature to validate their results, and found these settings performed adequately. The TRANSPOR2004 formulation (van Rijn 2007a, b) has been used successfully in other sand transport and headland bypassing studies (Grunnet et al., 2004; Luijendijk et al., 2017; McCarroll et al., 2018; Valiente et al., 2020). Accordingly, the settings included in Appendix A were used in this study.

Overall, good or excellent skill across most comparisons, and in particular, generally good or excellent skill predicting near-bed velocity components off the northern headland of Perranporth, indicates the suitability of this model to investigate sand transport at the coastal scale and headland bypassing.

This article is protected by copyright. All rights reserved. 

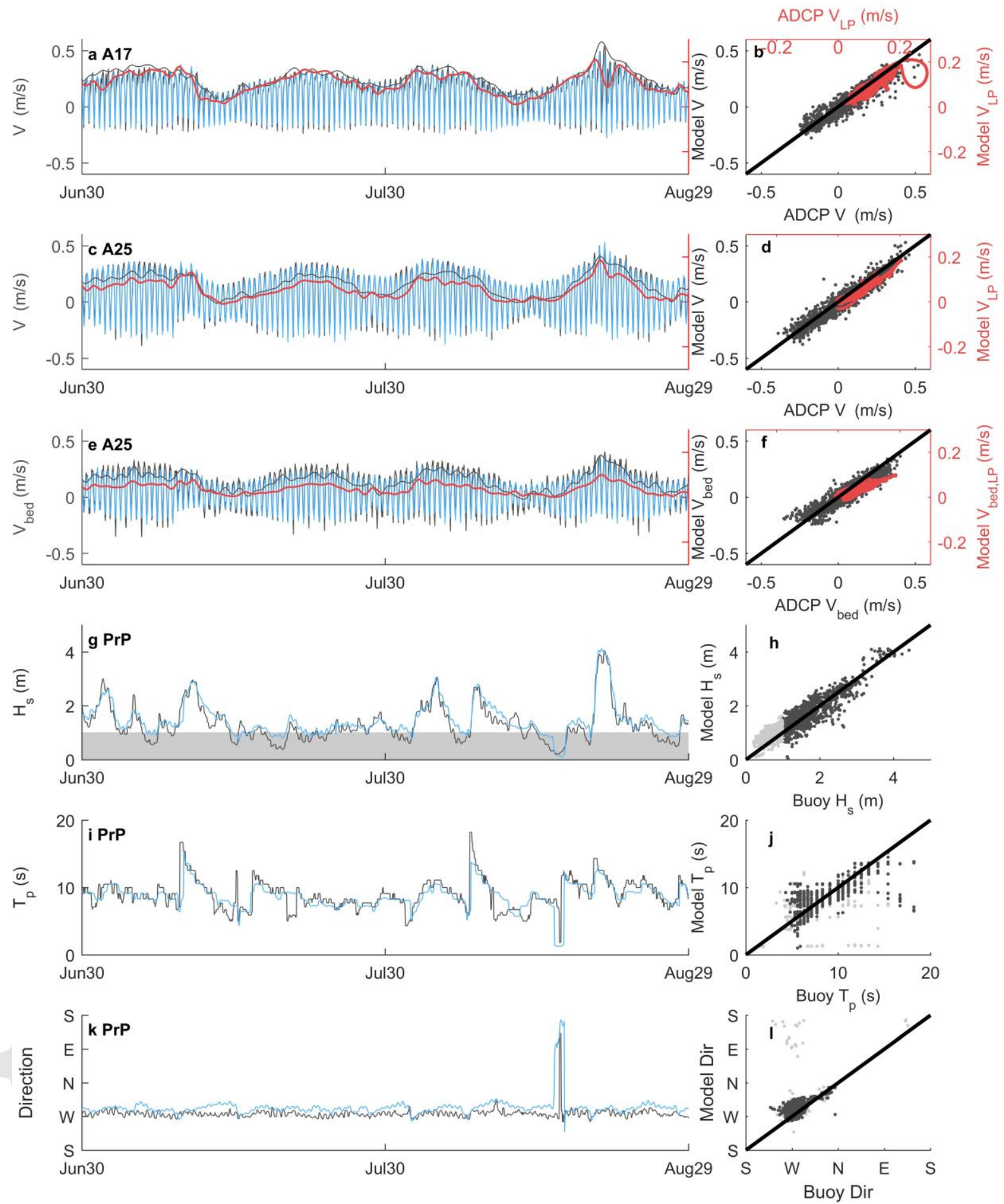

Figure 5: Validation time series and scatter plots. Observation time series are dark grey, modelled time series are blue. Where residual (low-pass) time series are shown (a, c, e), observations are dark grey and model data are red. Dark grey points in the scatter plots are hourly unfiltered data of model vs observation, red data are low-pass filtered data $\left(\mathrm{V}_{\mathrm{LP}}\right)$, and light grey data $(\mathrm{h}, \mathrm{j}, \mathrm{I})$ show data for $H_{s}<1 \mathrm{~m}$. The black line (scatter plots) indicates a perfect 1:1 agreement. (a-d) Depth-averaged northward velocity components from the Perranporth ADCP deployments A17 and A25. (e, f) Near bed northward velocity components at ADCP deployment A25. $(\mathbf{g}, \mathbf{h})$ Significant wave height at the Perranporth wave buoy. Data for $H_{s}<1 \mathrm{~m}$ are highlighted in light grey here and in subsequent scatter plots. (I, j) Spectral peak wave period at the Perranporth wave buoy. (k, l) Mean wave direction at the Perranporth wave buoy. Wave buoy data are median filtered for clarity.

This article is protected by copyright. All rights reserved. 
Table 1

Model Validation Statistics for Currents and Waves, including Residuals from Low-Pass

Filtering.

\begin{tabular}{|c|c|c|c|c|c|c|c|c|c|c|c|c|c|c|}
\hline \multicolumn{15}{|c|}{ Currents $\left(\mathrm{ms}^{-1}\right)$} \\
\hline \multicolumn{8}{|c|}{ Unfiltered Signal } & \multicolumn{7}{|c|}{ Low-Pass Residual } \\
\hline Location & $\mathrm{N}$ & \multicolumn{2}{|r|}{$\mathrm{R}^{2}$} & BIAS & MAE & WIA & BSS & \multicolumn{2}{|l|}{$\mathrm{N}$} & $\mathrm{R}^{2}$ & BIAS & MAE & WIA & BSS \\
\hline A17-E & 2208 & & 0.04 & $3 e-3$ & 0.02 & 0.30 & 0.08 & \multicolumn{2}{|c|}{2208} & 0.02 & $2 e-3$ & 0.01 & 0.29 & 0.22 \\
\hline A17-N & 2208 & & 0.88 & -0.01 & 0.03 & 0.83 & 0.92 & \multicolumn{2}{|c|}{2208} & 0.71 & -0.01 & 0.02 & 0.69 & 0.75 \\
\hline $\begin{array}{l}\text { A17-E } \\
\text { (bed) }\end{array}$ & 2208 & & 0.01 & $-2 e-3$ & 0.02 & 0.31 & 0.09 & \multicolumn{2}{|c|}{2208} & $3 e-3$ & $-3 e-3$ & 0.01 & 0.14 & -0.02 \\
\hline $\begin{array}{l}\text { A17-N } \\
\text { (bed) }\end{array}$ & 2208 & & 0.82 & -0.02 & 0.04 & 0.75 & 0.84 & \multicolumn{2}{|c|}{2208} & 0.60 & -0.02 & 0.02 & 0.55 & 0.53 \\
\hline A25-E & 1538 & & 0.06 & -0.02 & 0.04 & 0.47 & 0.09 & \multicolumn{2}{|c|}{1538} & $3 e-4$ & -0.02 & 0.02 & $-5 e-3$ & -0.66 \\
\hline A25-N & 1538 & & 0.93 & -0.02 & 0.04 & 0.87 & 0.96 & \multicolumn{2}{|c|}{1538} & 0.90 & -0.02 & 0.02 & 0.71 & 0.91 \\
\hline $\begin{array}{l}\text { A25-E } \\
\text { (bed) }\end{array}$ & 1538 & & 0.05 & -0.02 & 0.04 & 0.46 & 0.06 & \multicolumn{2}{|c|}{1538} & 0.01 & -0.02 & 0.02 & -0.09 & -0.99 \\
\hline $\begin{array}{c}\text { A25-N } \\
\text { (bed) }\end{array}$ & 1538 & & 0.88 & -0.02 & 0.05 & 0.81 & 0.91 & \multicolumn{2}{|c|}{1538} & 0.82 & -0.02 & 0.03 & 0.61 & 0.83 \\
\hline ALL-E & 3746 & & 0.04 & -0.01 & 0.03 & 0.48 & 0.16 & \multicolumn{2}{|c|}{3746} & 0.21 & -0.01 & 0.01 & 0.56 & 0.33 \\
\hline ALL-N & 3746 & & 0.92 & -0.02 & 0.03 & 0.85 & 0.94 & \multicolumn{2}{|c|}{3746} & 0.84 & -0.02 & 0.02 & 0.72 & 0.84 \\
\hline $\begin{array}{l}\text { ALL-E } \\
\text { (bed) }\end{array}$ & 3746 & & 0.03 & -0.01 & 0.03 & 0.43 & 0.10 & \multicolumn{2}{|c|}{3746} & 0.08 & -0.01 & 0.02 & 0.39 & -0.08 \\
\hline $\begin{array}{l}\text { ALL-N } \\
\text { (bed) }\end{array}$ & 3746 & & 0.85 & -0.02 & 0.04 & 0.78 & 0.88 & \multicolumn{2}{|c|}{3746} & 0.73 & -0.02 & 0.02 & 0.60 & 0.66 \\
\hline \multicolumn{15}{|c|}{ Waves } \\
\hline & \multicolumn{5}{|c|}{$H_{s}(\mathrm{~m})$} & \multicolumn{6}{|c|}{$T_{p}\left(H_{s}>1 \mathrm{~m}\right)(\mathrm{s})$} & \multicolumn{3}{|c|}{$\operatorname{Dir}\left(H_{s}>1 \mathrm{~m}\right)\left(^{\circ}\right)$} \\
\hline Location & $\mathrm{N}$ & $\mathrm{R}^{2}$ & BIAS & WIA & BSS & $\mathrm{N}$ & $\mathrm{R}^{2}$ & BIAS & WIA & BSS & $\mathrm{R}^{2}$ & BIAS & WIA & MAE \\
\hline WHb & 2168 & 0.86 & 0.32 & 0.66 & 0.78 & 1634 & 0.51 & -0.14 & 0.70 & 0.71 & $0.01^{*}$ & 2.12 & 0.35 & 13.81 \\
\hline PrP & 2207 & 0.83 & 0.14 & 0.74 & 0.88 & 1372 & 0.49 & -0.12 & 0.70 & 0.72 & $0.26^{*}$ & 13.84 & 0.10 & 15.06 \\
\hline ALL & 4375 & 0.87 & 0.24 & 0.71 & 0.84 & 3008 & 0.58 & -0.15 & 0.73 & 0.76 & $0.04 *$ & 7.34 & 0.07 & 13.50 \\
\hline
\end{tabular}

Note. Brier skill scores are coded for excellent and good (bold), reasonable (italic) and poor (underlined) model skill. Eastward and Northward velocity components are denoted by "-E" and "-N" respectively. Near-bed currents are denoted by "(bed)". "ALL" indicates performance for combined data from A17 and $\mathrm{A} 25$.

* Circular correlation coefficient for directional data.

This article is protected by copyright. All rights reserved. 


\subsection{Headland and embayment morphology}

Selected quantified morphological parameters are displayed in Figure 6 for each headland (a, c, e and g) with summary statistics shown using boxplots in (b, $d, f$ and h). Parameters were quantified for upcoast and downcoast apparent morphologies for spring high and low water (SHW and SLW, respectively). For the purpose of this study, upcoast is defined as towards the northeast (increasing headland number). Headland morphology varies widely along this coast, and some headlands $(4,15$, 16 \& 22) cease to be apparent headlands at SLW, when the water line recedes beyond the headland apex. Headland cross-shore extent $X_{\text {head }}(\mathrm{a}, \mathrm{b})$ was seen to vary between circa $40 \mathrm{~m}$ and $1800 \mathrm{~m}$, and increase by around a factor 2 between SLW and SHW. $X_{\text {head, }}$, defined relative to the waterline on the beach and at the headland apex (Figure 4), tended to be smaller upcoast than downcoast which may predispose this coastline towards upcoast bypassing. Toe depth $Z_{\text {toe }}(\mathrm{c}, \mathrm{d})$ varied between circa $0.5 \mathrm{~m}$ and $17 \mathrm{~m}$, and was fairly constant between up and downcoast morphologies, whilst increasing between SLW and SHW by circa 3-4 m. Beach length $L_{b}(\mathrm{e}, \mathrm{f})$ varied between circa $50 \mathrm{~m}$ to $7500 \mathrm{~m}$, and decreased between SLW and SHW by around $1 / 3$ on average. Sediment coverage $R_{\text {sed }}(\mathrm{g}, \mathrm{h})$ was distributed between full sediment coverage to the DoT and circa $1 \%$ coverage, and was similarly distributed between water levels and up and downcoast aspects. The wide range of morphologies represented here indicates the suitability of this region for testing the parameterisation of headland bypassing rates. Satellite imagery of each headland is presented in the supporting information (Figures S1-S9), for reference.

This article is protected by copyright. All rights reserved. 

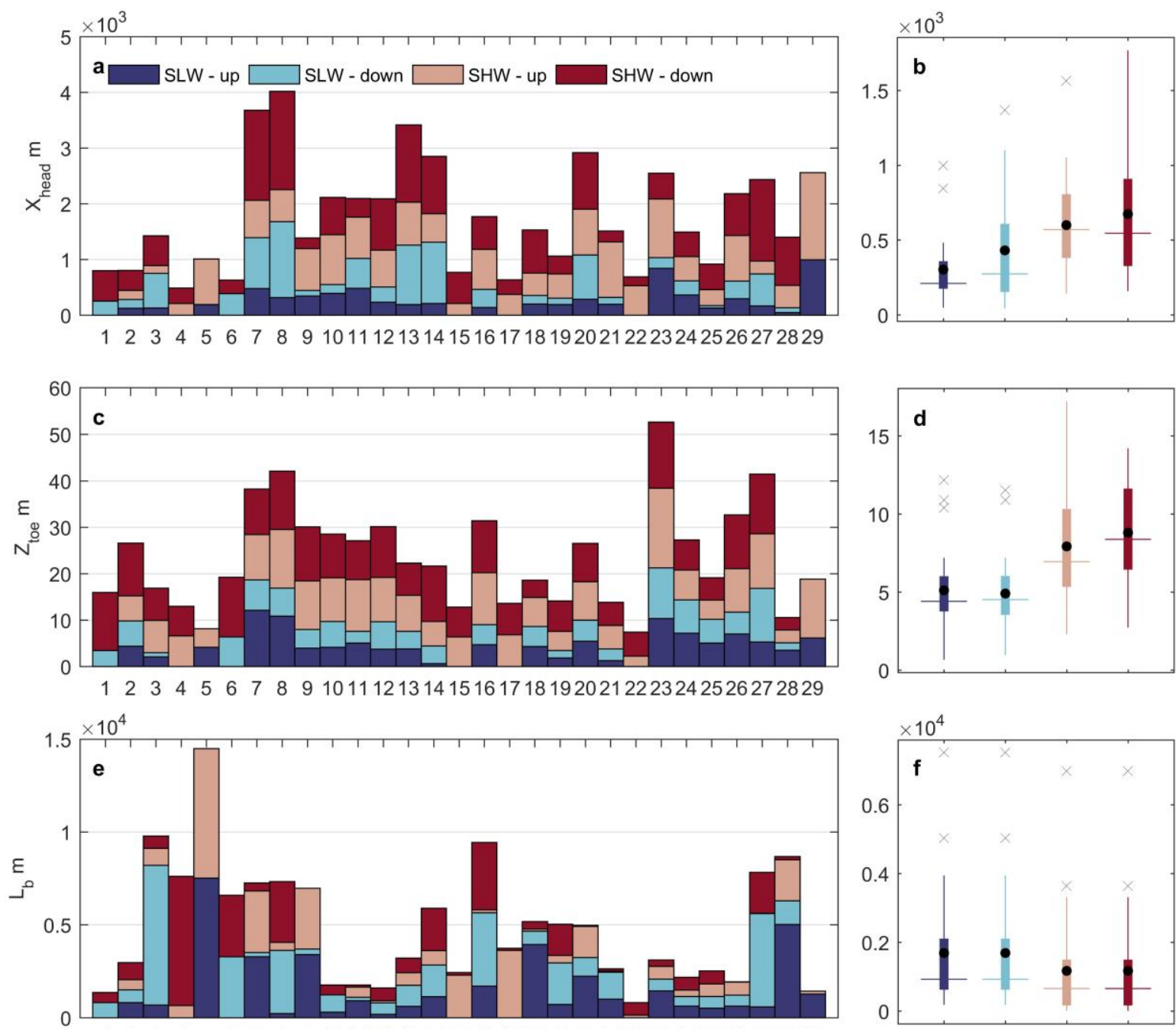

1223455678991011121314151617181920212223242526272829
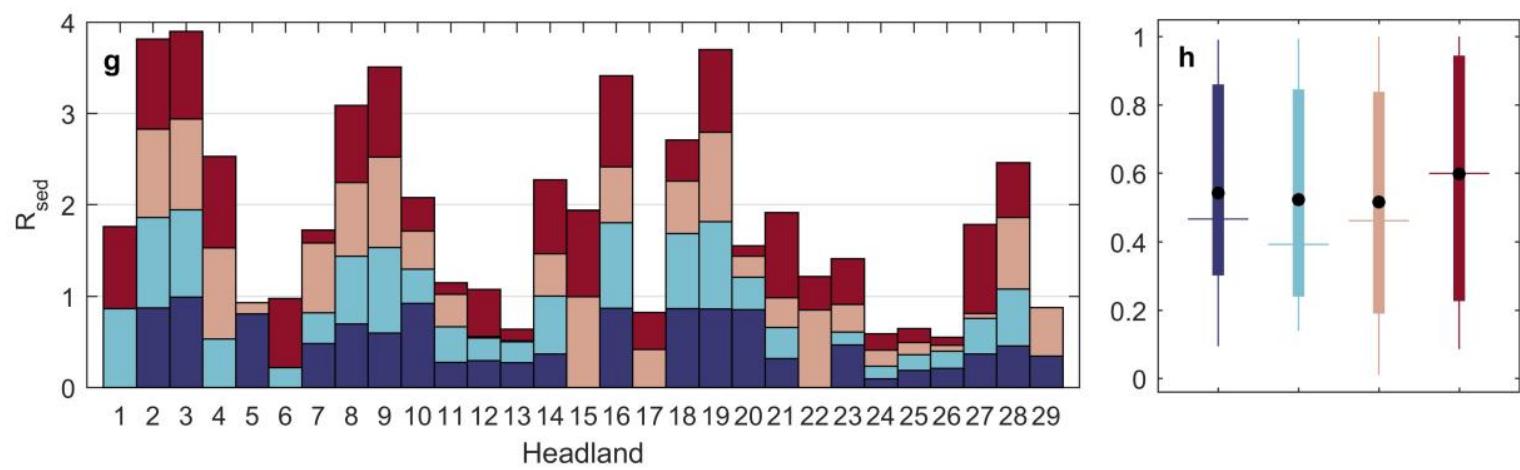

Figure 6: Summary figure of headland and bay morphological parameters including: headland crossshore length $X_{\text {head }}$, headland toe depth $Z_{\text {toe }}$, beach length $L_{b}$ and sediment ratio $R_{\text {sed. }}$. Stacked bar graphs $(a, c, e, g)$ show parameter values per headland for spring high water (SHW) and spring low water (SLW), and for the upcoast orientation (up) and downcoast orientation (down). Box plots (b, $d, f, h$ ) show summary statistics for each water level and headland orientation. The main body of the boxes span the $25^{\text {th }}$ and $75^{\text {th }}$ percentiles, the horizontal bar shows the median, the mean is shown (black dots), whiskers span up to $1.5 \times$ inter quartile range, and outliers are shown (black crosses). Satellite imagery of each headland is provided in the supporting information (Figures S1S9).

This article is protected by copyright. All rights reserved. 


\subsection{Headland bypassing}

Headland bypassing was active across 93\% (27/29) of headlands for at least one wave condition under wave-only forcing. Only two headlands (5-Godrevy Point \& 23 - Trevose Head) were closed to wave-forced bypassing under all tested conditions. Headland bypassing was blocked for at least one incident wave direction for $41.4 \%$ (12/29) of headlands under median (50\% exceedance) waves, for $27.6 \%(8 / 29)$ of headlands under large (5\% exceedance) waves, and $24.1 \%(7 / 29)$ of headlands for extreme (12 hour exceedance) waves. More headlands exhibited upcoast bypassing than downcoast. In this section we quantify the influence of environmental and topographic controls on headland bypassing and test and further develop the parameterisation of this process.

This section is subdivided into four parts: (1) starting with uniform sediment availability and wave-only forcing scenarios, we examine the influence of wave conditions and tidal elevations on bypassing rates; (2) we test the performance of the parameterisation of McCarroll et al. (2021; equation 1), and examine the effect of headland bathymetric expression (toe depth); (3) we compare uniform and nonuniform sediment scenarios under wave-only forcing; and (4), we quantify the impact of tidal currents for uniform and non-uniform sediments, including wave-current interactions.

\subsubsection{Effect of wave condition and tidal elevation}

Bypassing rates for wave-only scenarios are shown in Figure 7a-c. Sequential headlands with positive bypassing rates indicate a potential wave-forced upcoast sand transport pathway, while sequential negative bypass rates indicate a potential downcoast transport pathway. Data for different tidal elevations are differentiated with solid and dashed lines for SHW and SLW respectively. Headlands with zero net bypassing (including cases with divergent transport) under all conditions $(5,23)$ are considered closed to wave-forced sand bypassing. Comparisons with observed morphological changes over an energetic winter in bays adjacent to these blocking headlands is discussed in Section 5 (see also Text S2 and Figure S12 in the supporting information). Beyond headlands 1 and 29, model resolution decreases gradually towards the lateral boundaries. While the model resolution at these headlands is adequate, the full embayments on the outside of each of these headlands are not fully resolved (i.e., including the next headland along the coast). For this reason, bypassing into the region of interest at headlands 1 and 29 is excluded from analysis. Bypassing out of the region of interest at these headlands is not affected by this, and is included here.

The impact of tidal elevation on headland bypassing rates was independent of wave direction (Figure 7a-c). The relative impact of tidal elevation changes was greatest during median wave conditions, where in some cases bypassing was activated only at SLW. In other cases, bypassing direction changed between SHW and SLW, mainly for median wave conditions. The median impact of changing water

This article is protected by copyright. All rights reserved. 
levels decreases as wave height increases (Figure 7d). For median waves, bypassing at SLW has a median increase in magnitude of circa $4 \times$ relative to SHW, whereas this is reduced to circa $2.5 \times$ for large waves and circa $1.5 \times$ for extreme waves. When determining the mean increase in bypassing rate between SHW and SLW, large outliers were excluded for cases where SHW bypassing rates were very low $\left(Q_{b}<10^{-4} \mathrm{~m}^{3} \mathrm{~s}^{-1}\right)$, which affected median wave conditions. The mean increase in bypassing at SLW was around a factor of 2 relative to SHW. This relative change is driven by changes to apparent headland morphology at different water levels.

Bypassing rates were strongly dependent upon the cross-shore headland extent relative to surf zone width (Figure7e), in agreement with prior literature on headlands and groynes (McCarroll et al., 2021; Scott et al., 2016a). There was very little bypassing for $X_{\text {head }}>5 X_{\text {surf }}$ under all conditions, and for $X_{\text {head }}$ $>3 X_{\text {surf }}$ except where $\sin \left(2 \alpha_{b}\right)$ was high indicating oblique wave angles conducive to strong longshore transport. With a couple of exceptions, cases where bypassing was totally blocked fell within the region of $X_{\text {head }}>5 X_{\text {surf. }}$. Most model results where bypassing was active in this region of $X_{\text {head }}>5 X_{\text {surf }}$ indicated very low bypassing rates of circa $10^{-5}$ and $10^{-4} \mathrm{~m}^{3} \mathrm{~s}^{-1}$, or approximately $1-10 \mathrm{~m}^{3}$ day $^{-1}$. The greatest bypassing magnitudes occur for $X_{\text {head }} \lesssim 0.5 X_{\text {surf }}$. The influence of the ratio of $X_{\text {head }}: X_{\text {surf }}$ is clearest when plotted on a natural log scale (Figure 7e), indicating a likely exponential decay relationship between headland bypassing rate and headland extent for a given wave condition, in further support of the model proposed by McCarroll et al. (2021). This is explored further in the following section.

This article is protected by copyright. All rights reserved. 

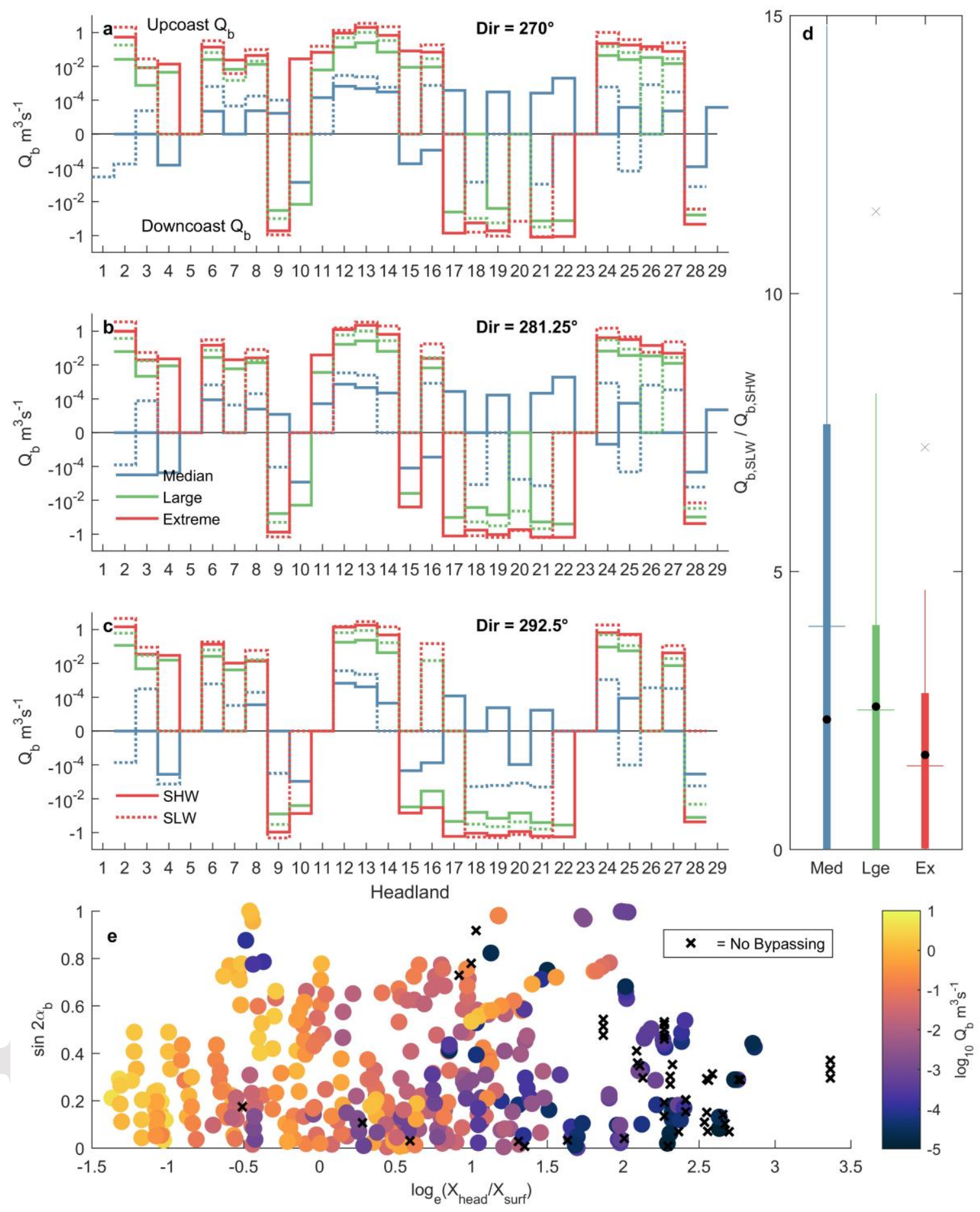

Figure 7: The influence of different wave conditions, wave direction and tidal elevation on headland bypassing rates for a uniform sand bed without tidal currents. (a-c) sand bypassing rates per each headland for median (blue), large (green) and extreme (red) wave conditions at spring high (solid) and low (dotted) water, and waves from (a) $270^{\circ}$, (b) $281.25^{\circ}$ and (c) $292.5^{\circ}$. Y axes are a $\log _{10}$ scale. Positive (negative) values are indicative of upcoast (downcoast) bypassing. (d) Boxplots summarising the ratio of bypassing rates at spring low vs high water with median (horizontal line), mean (black dot) and whiskers indicating $1.5 \times I Q R$. (e) Scatter diagram illustrating effect of wave breaking angle and surf zone width on bypassing rates using $\sin \left(2 \alpha_{b}\right)$ and $\log _{\mathrm{e}}\left(X_{\text {head }} / X_{\text {surf }}\right)$. Colours show bypassing magnitude on a $\log _{10}$ scale. Crosses denote cases with no bypassing.

This article is protected by copyright. All rights reserved. 


\subsubsection{Parameterisation and the influence of bathymetry}

The parameterisation of McCarroll et al., (2021), based on idealised isolated headlands with uniform bathymetric expression and uniform sediment availability (Equations $1 \& 2$ ), was tested against the bypassing rates shown in Figure 7 . These bypassing rates represent the most idealised conditions in this study, with uniform sediment availability and no tidal currents. Therefore, the primary differences in these data relative to the idealised conditions of McCarroll et al., (2021) are the bathymetric expression of the headland below the water line and the proximity of adjacent headlands.

A comparison of the modelled headland bypassing rates versus the parameterisation in Equation 1 is shown in Figure 8a. This includes bypassing rates from all wave scenarios and water levels. Headland $X_{\text {head }}$ was calculated separately for SHW and SLW, therefore this also represents the ability of the parameterisation to handle variability in tidal elevation. The original formulation greatly underestimates bypassing rates for the median wave conditions. A relatively minor alteration of the formulation of Equation 1 results in an improved fit to the bypassing rates predicted by the Delft3D model (Figure $8 b$ ), by changing the power in the exponent from 2 to 0.5 (Equation 5 ), effectively adjusting the slope of the exponential curve. This alteration mainly influences predictions in lowmagnitude bypassing conditions where $X_{\text {head }} \gg X_{\text {surf, }}$ and its implications are discussed in Section 5. For $X_{\text {head }}<0.5 X_{\text {surf }}$ the parameterised bypassing rate was set to $Q_{0}$ (McCarroll et al., 2021).

$$
Q_{b_{\_} A d j}=Q_{0} \cdot e^{-\left(\frac{X_{\text {head }}}{X_{\text {surf }}}\right)^{0.5}},
$$

There remains spread about the ideal fit 1:1 line with a MAE of a factor 4.3 and RMSE of a factor 6.5. This spread was hypothesised to be due to the influence of the variable bathymetric expression of the headlands and variable embayment morphology. A number of bathymetric and embayment morphological parameters were tested, including the bathymetric slope ratio of George et al. (2015), the beach length, headland separation, the degree of embaymentisation of Fellowes et al. (2019), headland longshore extent and headland toe depth in the form of $m_{t}$ (Equation 3). Most of these showed no clear relationship with the deviation of the predictions about the 1:1 line when compared qualitatively. Ultimately, the only parameter with a clear relationship to the deviation of the headland bypassing rates from the idealised solution was $m_{t}$ (Figure $8 \mathrm{c}$ ). An exponential term was fitted of the form:

$$
Q_{b_{-} T o e}=Q_{b_{-} A d j} \cdot e^{a-\frac{1}{\left(m_{t}-b\right)^{2}}},
$$

This article is protected by copyright. All rights reserved. 
Where $a$ and $b$ were calibration parameters. The best fit was found for $a=3.5$ and $b=0.7$, shown in Figure $8 \mathrm{~d}$. This improved the MAE of the parameter to a factor 3.5 and RMSE to a factor 5.2.

Bypassing directions were generally predicted correctly as a function of breaking wave direction relative to shore normal. The percentage of scenarios where bypassing was predicted correctly is shown in Figure 8e (grey bars) for each headland. Where there was no bypassing under any conditions, no bars are shown. Coloured bars with negative percentages indicate the percentage of scenarios where bypassing direction was wrongly predicted. The colours indicate the wave conditions where bypassing direction was predicted wrongly. For over half of headlands that had at least one bypassing direction wrongly predicted, the direction was wrong for median wave, low bypassing conditions or for only one or two scenarios. Six headlands had bypassing direction wrongly predicted for over $50 \%$ of cases. These are discussed in section 5 .

This article is protected by copyright. All rights reserved. 

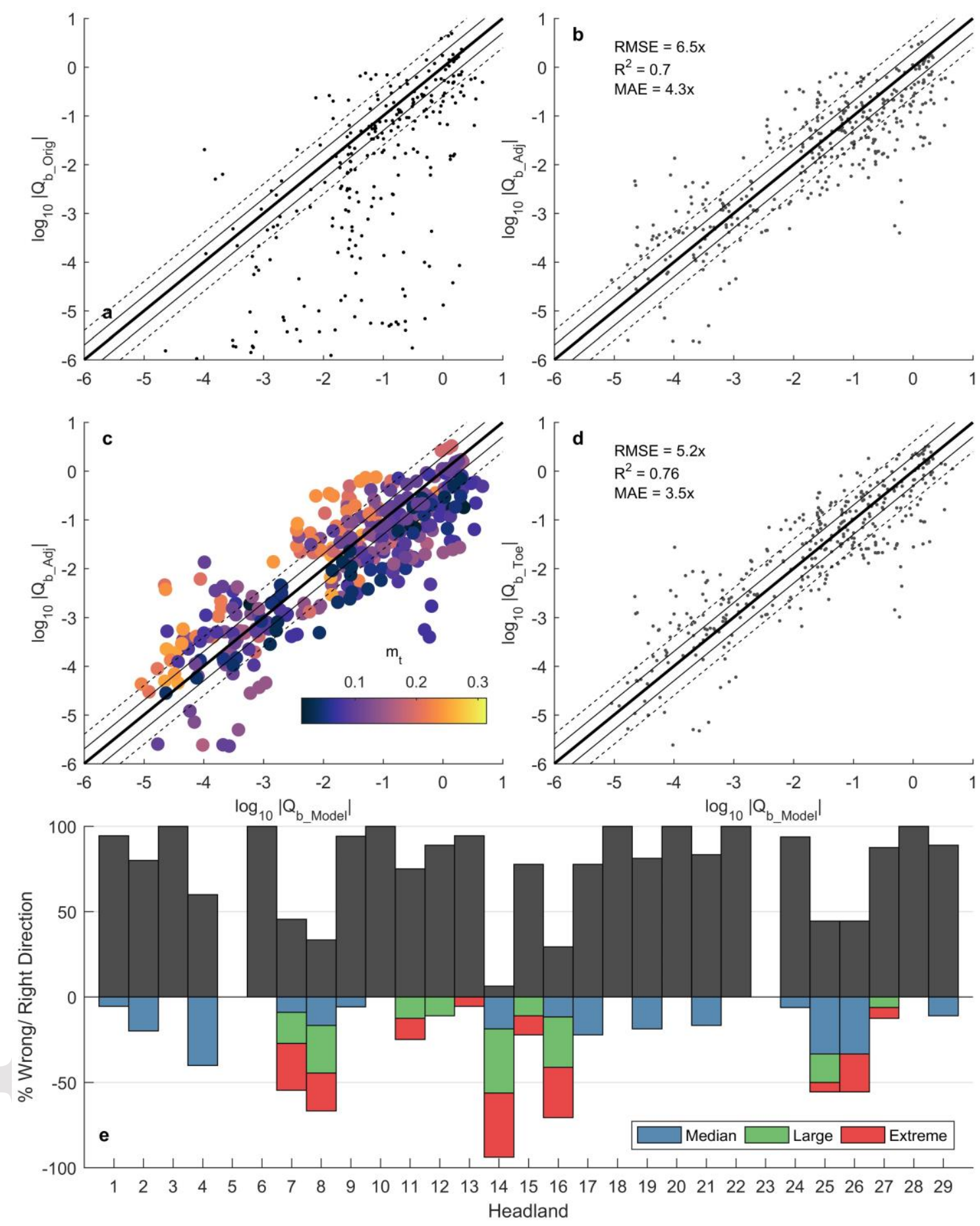

Figure 8: Comparison of headland bypassing parameterisations against the predictions of the Delft3D model. (a) The parameterisation taken directly from McCarroll et al. (2021), without adjustment $\left(Q_{b_{-} \text {orig }}\right)$, there are 135 outliers $(\mathrm{N}=402)$ where $Q_{b_{-} \text {orig }}$ predicted near zero bypassing. (b) The parameterisation of McCarroll et al. (2021), adjusted to better fit these data $\left(Q_{b_{-} A d j}\right)$. Statistics are shown, calculated using the log-transformed data and converted into factor errors where relevant. The 1:1 line for a perfect model is shown in black (thick line), a factor 2 deviation from the perfect model is shown with thin black lines, and a factor 4 with dashed black lines. (c) The parameterisation as in (b) with colours representing the $m_{t}$ parameter. (d) The parameterisation as in (b) with an additional term to account for variable depth off the headland toe via $m_{t}\left(Q_{b_{-} \text {Toe }}\right)$. (e) Percentage of scenarios where sand bypassing direction was correctly predicted (grey bars), or

This article is protected by copyright. All rights reserved. 
incorrectly predicted (coloured bars). Colours represent the wave conditions where bypassing direction was wrongly predicted. No bars are shown where no bypassing occurred, and percentages were calculated relative to the number of cases where bypassing occurred.

\subsubsection{The effect of spatially variable sediment coverage}

The impact of introducing spatially variable sediments was determined for each headland using the ratio:

$$
\frac{\Delta Q_{b_{-} S e d}}{Q_{b_{-} \text {Uni }}}=\frac{Q_{b_{-} \text {Sed }}-Q_{b_{-} \text {Uni }}}{Q_{b_{-} U n i}},
$$

Where $Q_{b_{-} S e d}$ represents bypassing for the non-uniform sediment coverage scenarios, and $Q_{b_{-}} u_{n i}$ represents bypassing for the uniform sediment scenarios. Results are presented in Figure 9a. The main impact of introducing a realistic sediment spatial coverage was that bypassing rates were generally reduced, or bypassing ceased altogether (ratio $=-1$; Figure 9a). Two headlands exhibited reversals in bypassing direction (ratio <-1) between the uniform and spatially variable sediment scenarios (Figure 9a). This occurred at headland 6 for median waves and a low bypassing magnitude, and headland 10 for large or extreme waves.

Eight headlands exhibited an activation of net bypassing in the case of non-uniformly distributed sediment for at least one wave condition, and a further five exhibited an increase in net bypassing rate, although this tended to be relatively small, never more than a factor 2 (ratio $=1$ ). In these cases, gross transport along the apex transect was greater for uniform sediments, however net bypassing was low or zero/ divergent. This was due to a relatively large magnitude divergent transport off the headland toe in the uniform sediment scenario which opposed alongshore transport past the headland further offshore, resulting in zero or low net bypassing for uniform sediment coverage. This nearshore transport divergence was of a much lower magnitude when sediment was unavailable for resuspension off the headland toe, and bypassing further offshore in the suspended load dominated (example: headland 11 - Figure 9d, e).

Two conditions were determined that were indicative of where a sediment availability parameter should be applied. Firstly, if $X_{\text {head }}<1.5 X_{\text {surf }}$ then bypassing was approximately equal to the uniform sediment availability case and a sediment availability parameter need not be applied. Likewise, if sediment is available off the headland toe (in this case tested at $100 \mathrm{~m}$ from the headland toe) then bypassing can be approximated using the uniform sediment parameterisation and the sediment parameter need not be applied. These conditions account for the headlands with zero or very small relative change in Figure 9a.

This article is protected by copyright. All rights reserved. 
For cases where these conditions indicate a change in bypassing rate due to sediment availability, a number of parameters were tested for influence on bypassing rates, including: cross-shore extent of sediment adjacent to the headland, sediment coverage ratio $R_{\text {sed }}, X_{\text {head }}, Z_{\text {toe, }}$, headland alongshore length and headland perimeter length. No parameters indicated a clear correlation with changes in bypassing rates predicted by the model. A uniform reduction of an order of magnitude performed best when applied to $Q_{b_{-} \text {Toe }}$ (Equation 6).

$$
Q_{b_{-} \text {Sed }}=0.1 \times Q_{b_{-} \text {Toe }} \text { for: } \frac{X_{\text {head }}}{X_{\text {surf }}}>1.5 \& \text { No sediment at headland toe, }
$$

Where the presence of sediment at the toe was determined at a distance of $100 \mathrm{~m}$ from the headland apex, along the apex transect, from the sediment polygons determined by the method described in section 3.3 and interpolated to the model grid. When applying the criteria discussed above with this parameter, the MAE for all headlands under the spatially variable sediment scenarios was reduced from a factor of 5.5 to a factor of 4.6 (Figure $9 b, c$ ). This indicates the parameters applied thus far are able to capture the order of magnitude of wave-forced instantaneous headland bypassing for different headland morphologies, at different tidal elevations, and for spatially variable sediments with an overall $\mathrm{R}^{2}$ of 0.66 . While an order of magnitude reduction under these conditions improves the overall skill of the parameterisation when all headlands are considered together, skill decreased for some individual headlands. This was associated mainly with two headlands (12 \& 24). Both of these headlands are highly asymmetric, with a shallower angle intersecting the beach on the side exposed to the dominant wave forcing, presenting less of a barrier to bypassing. The parameterisation consistently underestimated bypassing rates at these headlands during energetic wave events. This is discussed further in Section 5.1. This parameterisation does not consider limited sediment depth off the headland toe, which is likely to further limit potential bypassing where only a thin veneer of sediment is available at the toe. This is discussed in Section 5.2. It remains to test the influence of tidal currents on bypassing rates, which we address in the following section.

This article is protected by copyright. All rights reserved. 

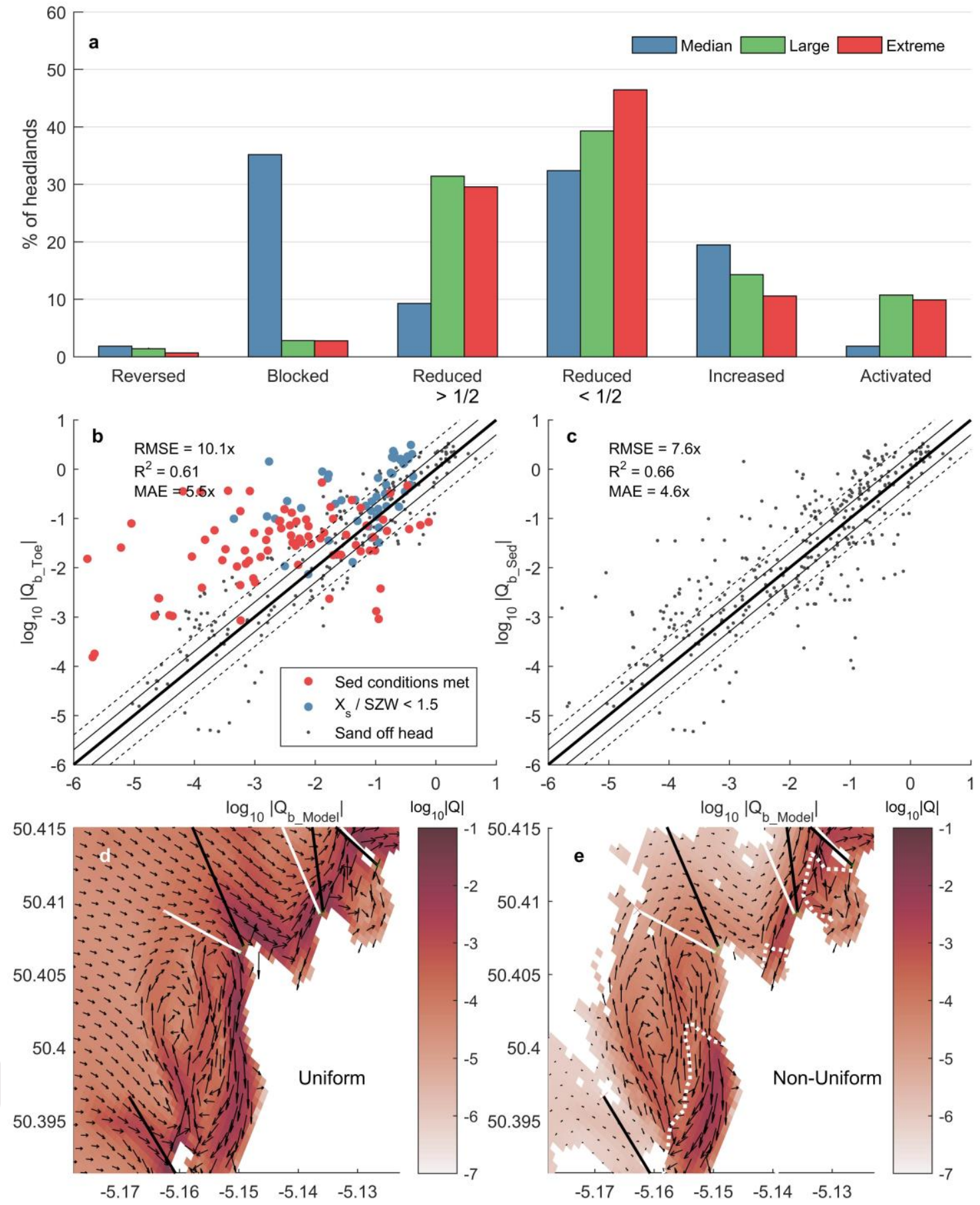

Figure 9: The effect of sediment availability of sand bypassing rates, and comparisons of headland bypassing parameterisations against the predictions of the Delft3D model. (a) The influence of limited sediment availability calculated as $\Delta Q_{b_{s} \text { sed }}=Q_{b_{-} \text {Sed }}-Q_{b_{-} \text {uni }}$ relative to the magnitude of bypassing for uniform sediments $\left(Q_{b_{-}} u_{n i}\right)$, categorised into key behaviours and presented as a percentage of all headlands. Bars are coloured for each wave condition. Bar values include all wave directions. (b) The parameterisation $Q_{b_{-} \text {Toe }}$ versus the Delft3D model. Statistics are shown, calculated using the log-transformed data and converted into factor errors where relevant. Colours indicate data where sediment was absent from the headland toe. Blue data indicate cases where $X_{\text {head }} / X_{\text {surf }}<1.5$. (c) The parameterisation of (b) with an added term to account for limited sediment availability. (d, e) Example headland (11 - Kelsey Head) where net bypassing was divergent for

This article is protected by copyright. All rights reserved. 
uniform sediments but upcoast for non-uniform sediments, with sand transport magnitude and vectors shown. Colours and vectors are log-scaled. The condition shown is extreme waves from $292.5^{\circ}$ at SHW. Dashed white lines in (e) indicate the offshore limit of sand coverage.

\subsubsection{Tidal currents and wave-current interactions}

To quantify the influence of tidal currents and wave-current interactions on headland bypassing, scenarios described above were repeated with the inclusion of tidal currents, including all wave conditions, and with uniform/ non-uniform sediment coverage. Tide-only scenarios were also conducted. Here, wave-current interactions refers to the combined influence of radiation stresses, Stoke's drift, enhanced bottom-friction and bed shear stress, refraction, current-induced Doppler shift, and wave blocking on headland bypassing rates (Booij et al., 1999; Dingemans et al., 1987; Soulsby et al., 1993; van Rijn, 2007a,b). Tidal currents at the times of SHW and SLW extracted for processing ranged between 0.02 and $1 \mathrm{~ms}^{-1}$ in magnitude off the headland apexes, with greater magnitude off larger promontories. Whilst these were not the peak ebb and flood currents, they represent a large range of velocities for the assessment of the impact of tidal currents on instantaneous bypass rates. Bypass rates were averaged over all times of SHW or SLW respectively. Example results are presented in Figure 10 (a-d) for the modal wave direction $\left(281.25^{\circ}\right)$ and at SLW (when bypassing rates tended to be larger). The same figure showing bypassing at SHW is provided in supplementary Figure S10.

Tidally-driven bypassing, in the absence of wave forcing, had a maximum magnitude of circa $10^{-3} \mathrm{~m}^{3} \mathrm{~s}^{-}$ ${ }^{1}$ across SHW and SLW in the case of uniform sediments (Figure 10a,b). The greatest bypassing magnitude for uniform sediments was off Trevose Head (headland 23), the largest promontory in the domain. This is driven by resuspension and transport of sediments off the headland apex by the amplified currents. When realistic sand coverage is considered, there is no sediment present off the apex of Trevose head and tide-only bypassing there is negligible for non-uniform sediments (Figure 10c,d). Tide-driven bypassing directions sometimes opposed the wave-driven bypassing. In this case, for median waves (Figure 10a), bypassing under combined wave-tide forcing tended to follow the tidedriven bypassing direction, indicating that median waves act to enhance sand transport in the tidal direction. For extreme waves (Figure 10b), bypassing direction rarely changed between wave-only and wave-tide scenarios (headland 15 at SHW only), and there was generally only a minor enhancement of bypassing magnitudes relative to wave-only scenarios. In some cases (headlands 20 (SHW) and 26) bypassing was switched off with the addition of tidal forcing.

Tide-driven bypassing was greatly reduced when non-uniform sediment coverages were included (Figure 10c-d). Bypassing was switched off across most headlands, and only active for seven headlands

This article is protected by copyright. All rights reserved. 
in total between SHW and SLW $(1,2,10,14,21,23 \& 27)$. In these cases, bypassing was generally downcoast (with the exception of 10 and 21 at SLW) and of very low magnitude. The greatest magnitude was for headlands 1 and 2 at SHW, which indicated tidally driven sand transport out of St Ives Bay to the west, in agreement with transport directions reported in King et al., (2019). Regardless of low tide-only bypassing rates, tidal currents were able to induce reversals in the median wave bypassing directions (Figure 10c) indicating that wave-current interactions are important during median waves, even when tide-only bypassing may be negligible.

This is indicated in the relative change bar plots for uniform sediments (Figure 10e) and non-uniform sediments (Figure 10f). Here, relative differences were averaged over the SHW and SLW scenarios and all wave directions. The largest relative differences tended to be for median waves (blue bars). There was also a widespread activation of bypassing under the wave-tide forcing when wave-only bypassing was nil, particularly for median and large waves.

This article is protected by copyright. All rights reserved. 

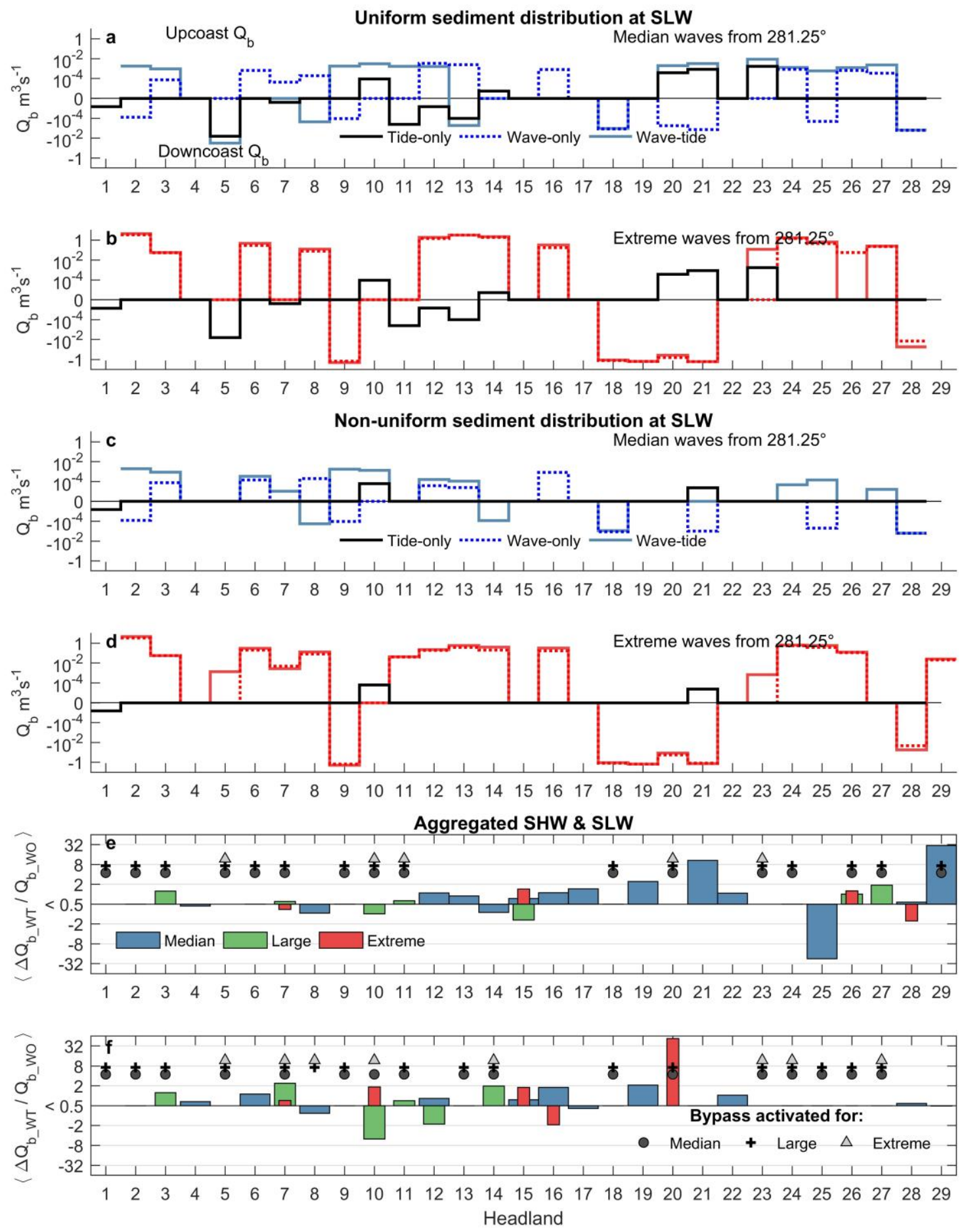

Figure 10: Comparison between tide-only, wave-only and wave-tide bypassing rates, for waves from the modal wave direction $281.25^{\circ}$. Instantaneous bypassing rates are presented for median and extreme waves for uniform sediments ( $a, b$ respectively) and non-uniform sediments ( $c, d$ respectively) for tide-only (black solid line), wave-only (coloured solid line) and wave-tide (coloured dashed line). Positive values represent upcoast bypassing, and downcoast bypassing for negative values. Values are for each headland. (e, f) Relative differences for uniform sediments (e) and nonuniform sediments ( $f$ ) per headland. Values are an average over all water levels and wave directions. Bars are coloured for each wave condition. Symbols indicate wave conditions where bypassing was activated by wave-tide forcing $Q_{b_{-} w T}$ but not by wave only forcing $Q_{b_{-} \text {wo }}$ for at least one condition. The $y$-scale increases in $\log _{2}$ increments.

This article is protected by copyright. All rights reserved. 
To quantify the relative impact of waves, tides and their non-linear interactions, bypassing rates were used to determine their wave-tide dominance classification as per King et al., (2019). This indicates whether the dominant driver of sand transport is tidal forcing $(T)$, wave forcing $(W)$ or the non-linear interactions between the waves and tides $(\mathrm{N})$ using two ratios:

$$
R 1=T:(W+N)
$$

$$
R 2=W: N \text {, }
$$

Where $W$ represents wave-only bypassing rate, $T$ represents tide-only bypassing rate and $N$ represents the contribution of non-linear wave-current interactions to bypassing, calculated as:

$$
N=W T-(W+T)
$$

Where $W T$ is the bypass rate under coupled wave-tide forcing. Results of the classification over all scenarios are presented in Figure 11. Lower-case letters indicate a sub-dominant contribution from the denoted forcing mechanism. There was no appreciable difference between wave directions, therefore all directions were aggregated to calculate the percentage of data in each class for each scenario wave scenario (columns) and waver level (rows). Median waves exhibit non-linear wave-tide interaction dominance of bypassing rates under all scenarios for the majority of headlands. At SLW around $10 \%$ of headlands shift from non-linear dominated to wave dominated under median waves, reflecting greater wave impacts at low water. The relative influence of tides under these waves is greatest at SHW, mainly manifested as a subdominant tidal contribution, denoted by a lower-case " $\mathrm{t}$ " (e.g. Nt). This reduces to $<5 \%$ of data at SLW.

Dominant forcing shifts towards wave-dominance as the wave exceedance increases (median $\rightarrow$ large $\rightarrow$ extreme). For large and extreme waves, the majority of bypassing is wave-dominated in this macrotidal environment at both SHW and SLW. For these waves and uniform sediments there is a secondary, tide dominated mode of sand transport for $~ 18 \%$ of data at SLW (Figure $11 \mathrm{e}-\mathrm{f}$ ). This occurs where wave-only bypassing was weak or negligible, for example at headland 23 . This signal is much reduced, or negligible, for non-uniform sediment coverages (Figure $11 \mathrm{~g}-\mathrm{I}$ ), reflecting the much reduced tidally driven bypassing when sediment is not available off large headland promontories. For extreme waves and non-uniform sediments (Figure 11i, I), wave-current interactions have a greatest impact at SLW, shifting the class of bypassing from $\mathrm{W}$ to $\mathrm{Wn}$ for around $30 \%$ of the data.

This article is protected by copyright. All rights reserved. 

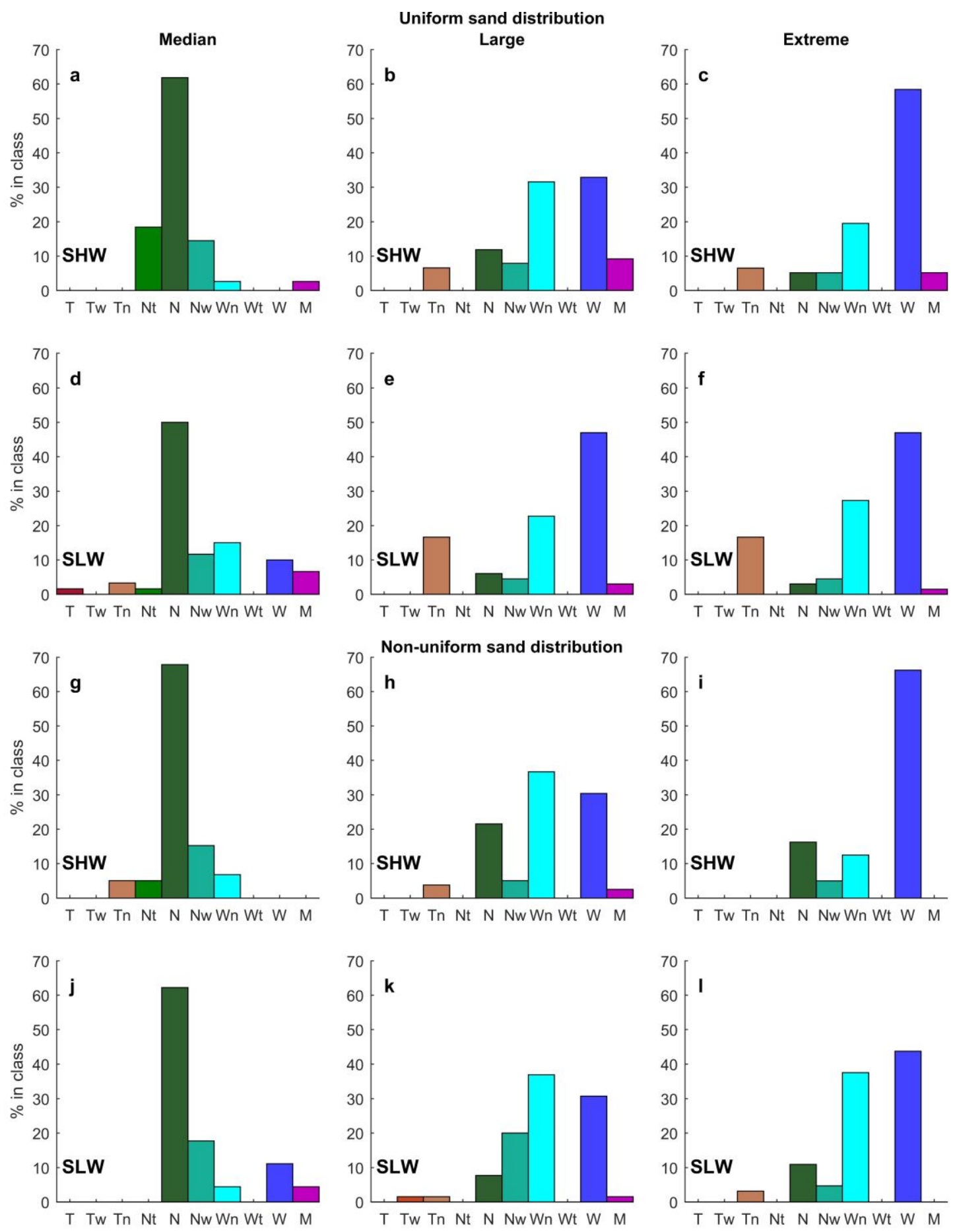

Figure 11: Wave-tide dominance classification as per King et al. (2019). Classifications range from tide-dominate (" $\mathrm{T}$ " - red) through dominance of non-linear wave-tide interactions (" $\mathrm{N}$ " - green) to wave dominated ("W" - blue), and mixed ("M" - purple). Lower-case letters denote a subdominant contribution from the denoted process. Data for all three wave directions were aggregated into median ( $50 \%$ exceedance, column 1$)$, large ( $5 \%$ exceedance) and extreme ( $12 \mathrm{~h}$ exceedance) wave conditions for simplicity. Classifications are shown for uniform $(a-f)$ and non-uniform ( $g-l)$ sediment coverage. Water levels are denoted by SHW and SLW for spring high and low water respectfully.

This article is protected by copyright. All rights reserved. 


\section{Discussion}

This paper tested the influence of wave, tide and morphological controls on instantaneous headland sand bypassing using a coupled wave-tide numerical model, and tested the performance of an existing parameterisation when applied to realistic headland morphologies and sediment coverage, making recommendations for additional terms to improve model performance. We discuss connectivity between embayments via headland bypassing along this stretch of coast in the context of previous work in this region and globally (Section 5.1). We then discuss the assumptions and limitations of the proposed bypassing parameterisation (Section 5.2), before outlining practical considerations for the application of a headland bypassing parameter with recommendations for further research (Section $5.3)$.

\subsection{Headland bypassing on embayed coastlines}

Prior studies on headland bypassing that consider wave and tidal forcing have established that bypassing is generally a wave-dominated process (George et al., 2019; McCarroll et al., 2018; Valiente et al., 2020; Vieira da Silva et al., 2018); however, the non-linear effects between waves and tidal forcing can be a major contributor to headland bypassing rates (Costa et al., 2019; Klein et al., 2020; McCarroll et al., 2018; Valiente et al., 2019a). Results presented here suggest that, in macrotidal environments, bypassing during energetic events (deep water $H_{s} \geq 6 \mathrm{~m}$ ) is wave-dominated; however, during median wave events (deep water $H_{s}=2 \mathrm{~m}$ ) bypassing rates are dominated by non-linear wavecurrent interactions between waves and tidal velocities, with waves enhancing bypassing in the tidal direction and activation of sand transport when tide-only bypassing is negligible.

Non-uniform sediment availability reduces tide-only bypassing when sand is not available adjacent to the headland apex, where tidal currents are amplified (King et al., 2019). Bypassing in these situations was in the suspended load. Tides have a greatest impact for median waves: tidal elevations modulate bypassing by a factor of 4 between SHW and SLW because of modulation of headland cross-shore length, whilst the impact of currents is generally not more than a factor of 2 for non-uniform sand coverage, matching the minor tidal control reported by Valiente et al. (2020). The primary control on bypassing rates is the cross-shore length of the headland relative to surf zone width (Figure 7e), and low bypassing rates for $X_{\text {head }} / X_{\text {surf }}>3$ matches McCarroll et al. (2021).

Reduced depth off the headland toe increases headland bypassing rates following the relationship in Equation 6. McCarroll et al. (2021) report an increase in bypassing magnitude of a factor 1.5 for headlands with sub-aqueous ridges of around 1 to $3 \mathrm{~m}$ prominence, resulting from increased orbital velocities at the bed off the headland. Equation 6 predicts this, as a decrease in depth off the headland toe of circa $2 \mathrm{~m}$ for depths between 3 and $10 \mathrm{~m}$ results in an increase in bypassing of a factor between

This article is protected by copyright. All rights reserved. 
1.3 and 1.8. This acts as an additional term to the parameterisation (Equations $5 \& 6$ ). A further related factor is the presence of headland-associated islands. Islands may increase blocking potential of a headland, depending on subaqueous ridge profile (e.g., George et al., 2015; McCarroll et al., 2021) and sediment availability. Four headlands in this study had associated islands $(5,10,11 \& 23)$. Of these, 5 and 23 predominantly block wave-forced bypassing, while 10 and 11 showed low or blocked waveforced bypassing over a large proportion of scenarios (Figure 7). This supports the notion that islands may impede bypassing, however further focussed study is required to quantify any effect islands may have.

The parameterisation of the form of Equations 1 and 5 had previously been shown to apply for an isolated headland with uniform offshore bathymetry, sediments and wave-only forcing (McCarroll et al., 2021). The alteration of the exponent between Equations 1 and 5 reduces the rate of decay of the bypassing parameter as headlands extend beyond the surf zone $\left(X_{\text {head }} / X_{\text {surf }}>1\right)$. This implies, for realistic headland morphologies and bathymetric expressions, headland bypassing occurs for greater relative headland cross-shore extents than predicted through idealised scenarios with a linear shoreface gradient.

We show that with this minor adaptation, and the addition of terms for variable headland toe depth (Equation 6) and sediment availability (Equation 8), instantaneous headland bypassing is amenable to parameterisation along stretches of coastline with realistic morphologies and spatial variability in sand coverage. The final parameterisation, for when both $X_{\text {head }}>1.5 X_{\text {surf }}$ and there is no sand at the headland toe, is:

$$
Q_{b_{-} \text {Sed }}=0.1 \times Q_{0} \cdot e^{-\left(\frac{X_{\text {head }}}{X_{\text {surf }}}\right)^{0.5}} \cdot e^{3.5-\frac{1}{\left(m_{t}-0.7\right)^{2}}},
$$

Else if $X_{\text {head }} \leq 1.5 X_{\text {surf }}$ or there is sand at the headland toe:

$$
Q_{b_{-} \text {Sed }}=Q_{0} \cdot e^{-\left(\frac{X_{\text {head }}}{X_{\text {surf }}}\right)^{0.5}} \cdot e^{3.5-\frac{1}{\left(m_{t}-0.7\right)^{2}}}
$$

Where $Q_{0}$ is the uninhibited longshore transport formulation of van Rijn (2014):

$$
Q_{0}=0.00018 \cdot K \cdot g^{0.5} \cdot \tan (\beta)^{0.4} \cdot D_{50}^{-0.6} \cdot H_{s, b}^{3.1} \cdot \sin \left(2 \alpha_{b}\right)
$$

This parameterisation is able to reproduce modelled bypassing rates with a MAE of a factor of 4.6, which suggests it is possible to predict the magnitude of instantaneous bypassing rates with some confidence and accuracy. The order of magnitude reduction associated with $Q_{b_{-} \text {sed }}$ improves

This article is protected by copyright. All rights reserved. 
parametrisation skill overall, however it was associated with a reduced skill for two headlands with a shallow angle of intersection with the beach on the exposed side to the dominant wave forcing. For these headlands, predicted bypass rates were underestimated. Headland orientation can promote unidirectional bypassing, with the angle between the headland and the adjacent shoreline altering the nature of the barrier to longshore transport presented by the headland (Wiggins et al., 2019; McCarroll et al., 2019). The influence of this, combined with limited sediment availability both spatially and in terms of sediment depth, are areas that warrant further focused research.

Bypassing directions were mainly predicted correctly using the breaking wave angle relative to shore normal (77\% of all cases), but with exceptions (23\%). Of those cases where direction was wrongly predicted, $43 \%$ were for median wave, low bypassing conditions, and the remainder were associated mostly with six headlands. To estimate the significance of this, the gross bypassing volume was estimated for each headland over a statistically representative year of hourly wave conditions (for more detail, see Text S1 in the Supporting Information). Over all 29 headlands considered in this study, $88.4 \%$ of gross wave-forced bypassing was estimated to be predicted correctly (see Figure S11). Of the $11.6 \%$ of bypassing volume estimated to be predicted wrongly, $7 \%$ was split between two headlands (headland 14 and 19).

For 5 headlands $(7,8,14,16 \& 25)$, $\gtrsim 50 \%$ of gross bypassing volume was estimated to be wrongly predicted. In these cases, longshore transport modelled at the beach was in the predicted direction, however sand transport offshore was directed in the opposite direction. This was driven by offshore sediment resuspension and transport, or strong embayment cellular circulation driving sediments offshore and around the upwave headland. Bypassing at headland 19 was only estimated wrongly for median waves at SHW, however bypassing was significant under this forcing (circa $0.01 \mathrm{~m}^{3} \mathrm{~s}^{-1}$ ) due to sediment resuspension at the headland toe. In cases where bypassing is significant under low-energy wave conditions with sediment present at the headland toe, this parameterisation should be used with caution as sand resuspension and transport at the toe may be affect the net bypassing direction when integrated across the headland transect.

Valiente et al. (2019b) suggested the concept of a 'river of sand' linking embayments along this stretch of coast through headland bypassing, based on observations of inter- and sub-tidal volumetric changes in response to environmental forcing at Perranporth. Bypassing magnitude and directions at Perranporth (headland 9) and the adjacent bays (headlands 7 -11) match predictions published previously, with northward bypassing during median wave conditions and southward bypassing for energetic wave forcing at Perranporth (McCarroll et al., 2018; Valiente et al., 2020). This lends confidence to the predictions of this model.

This article is protected by copyright. All rights reserved. 
Results presented here indicate widespread linkages between the embayments along this coastline, with only two headlands (5 - Godrevy Point \& 23 - Trevose Head) predominantly blocking longshore sand transport. These results are supported by results from Burvingt et al. (2017), who show beach morphological change along this coastline in response to the highly energetic winter of 2013/14, where 8-week mean $H_{s}$ peaked at $4.4 \mathrm{~m}$ with 22 storm-induced wave events (Oct - Apr; Scott et al., 2016b). The beach adjacent to Godrevy Point experienced significant net erosion. Modelling here predicts sand transport away from the Godrevy Point to the southwest, with no bypassing to act as sediment supply. The western side of Carbis Bay (Figure 1: between headlands 2 and 5) showed accretion, matching predictions of sediment bypassing headland 2 into the bay under energetic forcing

(Figure 7a-c), converging with sediment transport to the southwest from the beach adjacent to Godrevy Point. Likewise, Booby's Bay (between headland 22 and 23) experienced a large net erosion over this energetic winter. Headland bypassing is downcoast to the southwest along this section of coastline under energetic wave forcing (Figure 7 - headlands 17-22). With no sediment supply coming around headland 23 , this indicates erosion from this embayment, in agreement with observations. For greater detail, including an illustrated example of Carbis Bay, see Text S2 and Figure S12. The widespread linkages predicted here suggest that headland bypassing has the potential to be ubiquitous along exposed embayed coastlines.

\subsection{Assumptions and limitations}

The parameterisation terms presented in Equations 2, 5, 6, and 8 have been tested against a wide range of headland and bay morphologies, wave forcing conditions and tidal elevations. This parameterisation accurately predicts instantaneous bypassing magnitude in wave-dominated conditions. This study considers instantaneous bypassing rates, without considering morphology change and limited sediment depth. Whilst we do not consider different grain sizes here, grain size is accounted for in Equation 2, and its effects on bypassing rates are covered by McCarroll et al. (2021).

Morphology was kept constant to avoid feedback effects over the course of a simulation, keeping bed morphology constant and not considering limited sediment depth, enabling averaging over time under consistent forcing conditions for analysis. This enabled a constant morphology to be quantified and morphological controls such as headland toe depth to be determined. Thus, the results presented here do not account for cases where strong beach rotation drives accumulation of sediment against the downwave headland which facilitates bypassing (Wiggins et al., 2019), or where limited sediment depth constrains potential bypassing magnitude. Wishaw et al. (2021) demonstrate the potential importance of wave events sequencing to enable bypassing by transporting sediments to the headland

This article is protected by copyright. All rights reserved. 
apex. Thus, results presented here might be considered an upper limit for a given bed morphology and spatial sediment coverage.

The parameterisation does not account for tidal currents and their interactions with waves, or wind driven currents. Vieira da Silva et al. (2018) found that waves drove sand bypassing at a rate two orders of magnitude greater than wind-driven currents. Our results suggest that bypassing is wavedominated during energetic events, even in a macrotidal environment; however, wave-current interactions are dominant for median wave conditions. Thus, we recommend caution when applying the parameter for median waves in macrotidal environments as wave-current interactions can be dominant. The parameterisation accounts for varying tidal elevation through changes to the apparent headland morphology (changes to $X_{\text {head }}$ and $Z_{\text {toe }}$ ).

There is a scarcity of observations of headland bypassing rates. Observations during low energy conditions have been made by tracer experiment (Duarte et al., 2014) and sand trapping (Vieira da Silva et al., 2016). In other cases, volumetric changes have been used to infer bypassing (George et al., 2018; Klein et al., 2010; McCarroll et al., 2019; Valiente et al., 2019b; Wiggins et al., 2019). Thus, bypassing rates presented here could not be validated directly, and validation relied upon validation of current velocities, including near-bed velocities, and comparison of bypassing magnitudes to those reported elsewhere using different models (McCarroll et al., 2018, 2021; Valiente et al., 2020), whilst using transport formulae and settings used elsewhere under similar conditions (King et al., 2019; Luijendijk et al., 2017; McCarroll et al., 2018; van Rijn, 2007a, b). Thus, absolute bypassing magnitudes presented here should be considered exploratory in nature.

Whilst the parameterisation on which this work builds (McCarroll et al., 2021; Equation 1) is based on idealised headland morphologies, and is thus not optimised to any single location, the additional parameterisation terms applied in this study for headland toe depth and sediment coverage should be considered optimised for the North Coast of Cornwall, UK. Further work is required to examine the applicability of these terms to other coastlines, and against other methods of estimating headland bypassing potential. Testing of this parameterisation in regions with contrasting tidal and wave conditions (e.g., microtidal, wind-sea dominated; Vieira da Silva et al., 2018), varied headland, embayment and nearshore morphologies (Duarte et al., 2014; George et al., 2015), different sediment characteristics (e.g., gravel; Wiggins et al., 2019; McCarroll et al., 2019, 2021), and against estimates of headland bypassing potential such as the headland bypassing ratio of George et al. (2019) would support the development and generalisation of the parameters developed here.

This article is protected by copyright. All rights reserved. 


\subsection{Implications for coastal modelling}

In this section, we summarise the key considerations arising from this research with implications for those modelling long-term shoreline change. Figure 12 summarises the key findings relating to instantaneous headland bypassing on embayed coastlines.

The results of this study are of particular interest to those engaged in development and application of long-term hybrid shoreline models, where the parameterisation of headland bypassing enables efficient computation of bypassing magnitude for a large number of conditions. Many of these models do not directly incorporate headland bypassing (e.g., Antolínez et al., 2019; Robinet et al., 2018, 2020; Toimil et al., 2017; Vitousek et al., 2017). The one-line longshore transport model of Roelvink et al. (2020) includes a parameterisation of headland bypassing, however this approach is for a simple groyne without consideration of more complex factors present in realistic headlands such as variable sediment coverage. For an approach that robustly deals with bypassing, it is necessary to include computationally intensive process based components to estimate sediment transport (e.g., MIKE STSM by DHI; Drønen et al., 2011; Kristensen et al., 2012). Therefore, development of bypassing parameterisations is of direct benefit to these efforts, and the parametric approach described in this paper could be incorporated into any of the above mentioned hybrid approaches. In applying the parameterisation presented in this paper, the following should be considered:

1. Quantifying morphometric parameters:

a. For pocket beaches where it is difficult to determine the beach orientation, or beach orientation is highly oblique to the orientation of the adjacent coastlines up and downcoast, it is recommended to take the orientation of the nearest adjacent stretch of open beach or the general orientation of the coastline.

b. Headland transects and morphology should be determined as described in McCarroll et al. (2021; their section 5) with the addition of toe depth along the apex transect (50 $\mathrm{m}$ from the headland toe) as shown in Figure 4/ Figure 12d.

c. It should be determined if sediment is present at the headland toe, for example from high-resolution bathymetry using the method described in Section 3.2.1 (Figure 2). It is recommended that for sediment to be classed as present, a continuous, uninterrupted sediment coverage be present for an area of $2500 \mathrm{~m}^{2}(50 \times 50 \mathrm{~m})$ at $100 \mathrm{~m}$ from the headland apex, for maximum comparability with the modelled approach in this study ( $50 \mathrm{~m}$ reflecting the model resolution at headlands here).

d. Repeat the process for beaches adjacent on the up- and downcoast headland aspects, giving an upcoast and downcoast morphology (Figure 4).

This article is protected by copyright. All rights reserved. 
2. Wave forcing:

a. A method for transformation of waves from offshore to the breakpoint is presented in McCarroll et al., (2021) using linear wave theory and van Rijn (2014).

3. Unconstrained longshore flux:

a. An estimate of unconstrained flux alongshore $Q_{0}$, can be determined using van Rijn (2014); Equation 2/ 14.

4. Wave-forced bypassing estimation:

a. Using Equations 12/ 13, an estimation of wave forced bypassing can be determined for a given stretch of coast. These should be applied bearing the following points in mind:

b. For $X_{\text {head }}>5 X_{\text {surf, }}$ bypassing can be assumed to be very low or negligible (Figure 7e; Figure 12a);

c. Equation 13 applies to all other cases, determining the constraint on longshore flux due to the headland (Figure 12b);

d. For $X_{\text {head }}<0.5 X_{\text {surf, }}$, the unconstrained longshore flux should be applied (Equation 2/ 14), and the headland assumed to not block bypassing (Figure 12c);

e. Equation 12 applies instead of Equation 13 only when sediment is not available off the headland apex, and $X_{\text {head }}>1.5 X_{\text {surf }}$ (Figure 12e).

This article is protected by copyright. All rights reserved. 


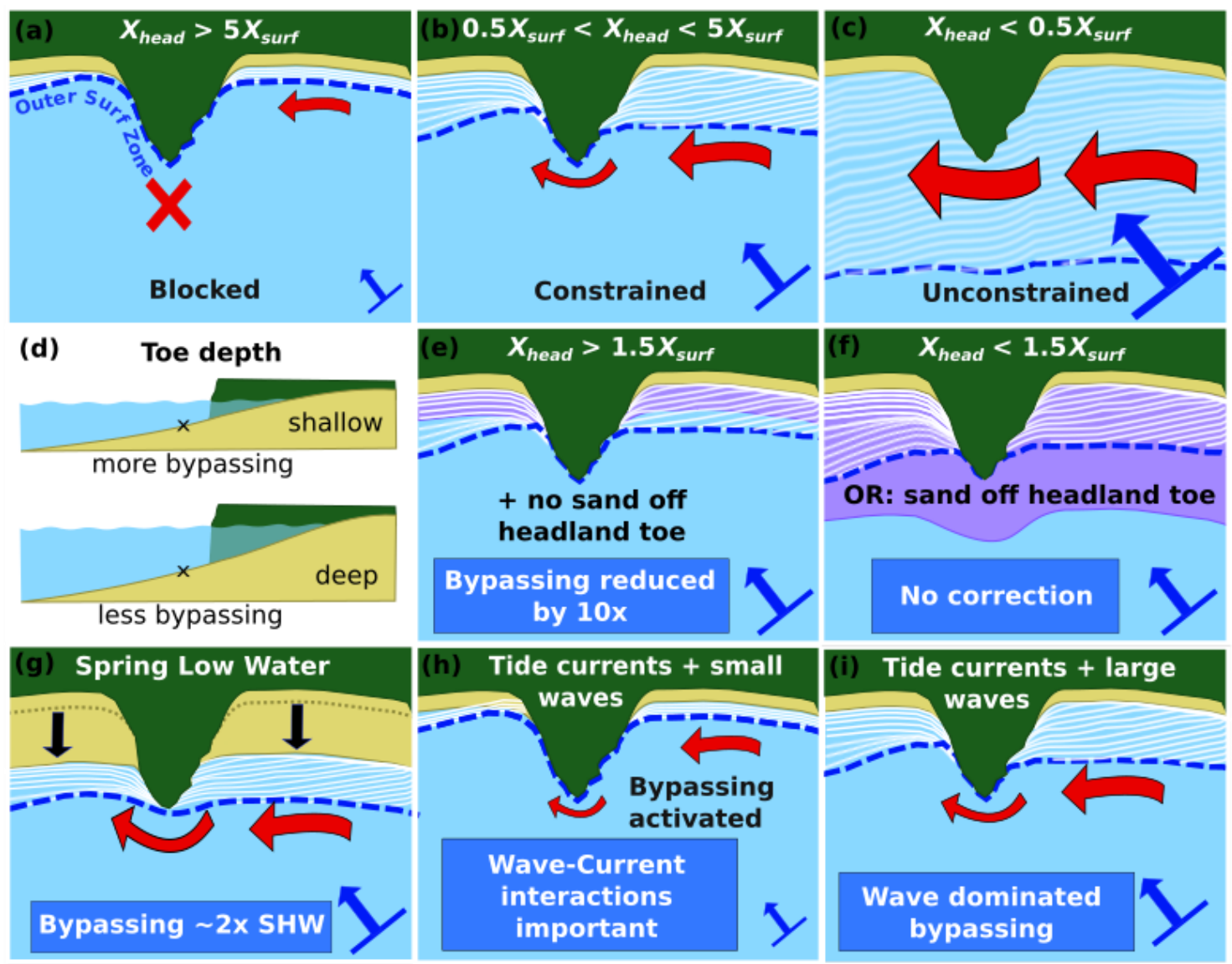

Figure 12: Summary schematic cartoon indicating key findings related to instantaneous headland bypassing. Non-erodible headlands and hinterland is shown in Green, sandy beaches are yellow and seawater is blue. Red arrows show simplified sand transport pathways for indicative purposes, scaled to show increasing and decreasing magnitude of net sand transport. Blue arrows indicate wave power and direction. The blue dashed line indicates the outer limit of the surf zone (white lines indicate of wave breaking). Purple polygons indicate subaqueous sand coverage $(e, f)$.

In macrotidal environments and low wave energy, it may be prudent to assess the dominant transport mode to check the applicability of this parameter. The parameter may underestimate transport or predict bypassing in the wrong direction where wave-current interactions are important. This tended to be for low wave energy and spring tides in this macrotidal environment (King et al., 2019; Figure 12h). Variable sediment depth is not accounted for in this parameter, as discussed in Section 5.2. Understanding the role of spatially variable sediment depth in constraining headland bypassing rates needs to be addressed through further research. In this context, these results and this parameter may represent an upper estimate of potential bypassing rates.

To constrain the applicability of this parameter in cases where bypassing could be dominated by wavecurrent interactions, a means of determining the dominant sand transport mode under specific wave and tide conditions without a computationally expensive numerical model could be of benefit. This would be an application and extension of the classification scheme of King et al., (2019). King et al. (Under Review) highlight potential for the prediction of wave-tide dominance of sand transport based

This article is protected by copyright. All rights reserved. 
on readily available predictors such as tide range, maximum current speed, significant wave height, peak period, direction and depth.

\section{Conclusions}

A validated 3D numerical model (Delft3D) was developed for a $75 \mathrm{~km}$ stretch of macrotidal, exposed coastline to investigate environmental and morphological controls on headland sand bypassing. Three wave exceedance conditions were tested ( $50 \%, 5 \%$ and 12 hour) from three directions, with both uniform and variable sediments, with and without tidal currents. Headland morphology was generally asymmetric, suggesting a predisposition to bypassing towards the northeast along the North Coast of Cornwall.

Headland bypassing is strongly dependent upon headland cross-shore extent relative to surf zone width. When cross-shore length exceeds five surf zone widths, bypassing is effectively negligible. Headland toe depth represents an important secondary control on bypassing magnitude, through moderation of wave impacts off the headland toe. Sediment spatial variability can reduce bypassing by several orders of magnitude depending on the relative coverage of sand adjacent to the headland, and reduces the effect of tidal currents relative to a uniform sand bed.

Tidal elevations are a secondary control on bypassing during energetic wave events, and have a greater relative impact during median wave energy conditions. The impact of tidal elevations is largely through modifications of the apparent morphology of the headland and in this macrotidal environment modulates bypassing rates by a factor of 4 on average for median wave energy, and a roughly factor 2 for energetic waves. Tidal currents have a minor effect during energetic waves, however they have a greater impact for median wave energy conditions through non-linear wave tide interactions. Wave-current interactions can dominate bypassing during median wave energy conditions at spring tides.

An existing parameterisation based on an isolated headland with uniform offshore bathymetry was tested against bypassing with realistic embayment morphologies, and additional terms for headland toe depth and sediment availability were explored. Bypassing rates were predicted with mean absolute error of a factor 4.6. Generalised estimations of bypassing in realistic settings are entirely novel, therefore any predictor within an order of magnitude is highly useful. These results indicate wave-dominated bypassing is amenable to parameterisation in embayed settings.

This article is protected by copyright. All rights reserved. 


\section{Acknowledgements}

We acknowledge the UK Hydrographic Office for the VORF corrections and single-beam bathymetry. High-resolution bathymetry here contains public sector information, licensed under the Open Government Licence v3.0, from the Maritime and Coastguard Association. We acknowledge the MET Office (Andy Saulter) for the hydrodynamic and wave forcing data and NOAA for the atmospheric pressure and wind data, and EMODnet bathymetry Consortium for the EMODnet Digital Bathymetry (DTM 2016). This research was supported by the NERC-funded BLUECoast Project (NE/NO15525/1). The data on which this paper is based are publicly available from the corresponding author and online via the University of Plymouth PEARL open access research repository. Model input files are available here: http://hdl.handle.net/10026.1/17351. Processed data including modelled and parameterised bypassing rates, headland morphometric parameters and environmental and topographic parameters are available here: https://pearl.plymouth.ac.uk/handle/10026.1/17350.

\section{References}

Ab Razak, M. S., Dastgheib, A. \& Roelvink, D. (2013). Sand bypassing and shoreline evolution near coastal structure, comparing analytical solution and XBeach numerical modelling. Journal of Coastal Research, 65, 2083- 2088.

Acworth, C. \& Lawson, S. (2012). The Tweed River entrance sand bypassing project, ten years of managing operations in a highly variable coastal system. Proceeding of the 20th NSW Coastal Conference 2012 Tweed Head, $1-23$.

Akan, C., McWilliams, J. C. \& Uchiyama, Y. (2020). Topographic and coastline influences on surf Eddies. Ocean Modelling, 147, 101565. https://doi.org/10.1016/j.ocemod.2019.101565

Antolínez, J. A., Méndez, F. J., Anderson, D., Ruggiero, P., \& Kaminsky, G. M. (2019). Predicting Climate-Driven Coastlines With a Simple and Efficient Multiscale Model. Journal of Geophysical Research: Earth Surface, 124(6), 1596- 1624.

Bentamy, A., \& Fillon, D. C. (2012). Gridded surface wind fields from Metop/ASCAT measurements. International Journal of Remote Sensing, 33(6), 1729 - 1754. https://doi.org/10.1080/01431161.2011.600348

Booij, N., Holthuijsen, L. H., \& Ris, R. C. (1999). A third-generation wave model for coastal regions 1. Model description and validation. Journal of Geophysical Research, 104(C4), 7649 - 7666. https://doi.org/10.1029/98JC02622

Bricheno, L. M., Wolf, J., \& Aldridge, J. (2015). Distribution of natural disturbance due to wave and tidal bed currents around the UK. Continental Shelf Research, 109, 67- 77. https://doi.org/10.1016/j.csr.2015.09.013

Burrough, P. A. (1981). Fractal dimensions of landscapes and other environmental data. Nature, 294, $240-241$.

This article is protected by copyright. All rights reserved. 
Burvingt, O., Masselink, G., Russell, P. \& Scott, T. (2017). Classification of beach response to extreme storms. Geomorphology, 295, $722-735$.

https://doi.org/10.1016/j.geomorph.2017.07.022.

Castelle, B. \& Coco, G. (2012). The morphodynamics of rip channels on embayed beaches.

Continental Shelf Research, 43, 10-23.

https://doi.org/10.1016/j.csr.2012.04.010

Castelle, B. \& Coco, G. (2013). Surf zone flushing on embayed beaches. Geophysical Research Letters, 40, $2206-2210$. https://doi.org/10.1002/grl.50485

Castelle, B., Scott, T., Brander, R. W. \& McCarroll, R. J. (2016). Rip current types, circulation and hazard. Earth-Science Reviews, 163, 1 - 21.

Castelle, B., Dodet, G., Masselink, G., \& Scott, T. (2018). Increased winter-mean wave height, variability and periodicity in the North-East Atlantic over 1949-2017. Geophysical Research Letters, 45, $3586-3596$. https://doi.org/10.1002/2017GL076884

Collins, M. B. (1987). Sediment transport in the Bristol Channel: A review. Proceedings of the Geologists' Association, 98(4), $367-383$. https://doi.org/10.1016/S0016-7878(87)80076-7

Costa, W. L. L., Silveira, L. F. \& Klein, A. H. F. (2019). Influence Of Wave Climate And Tidal Regime On Headland Bypassing - Study Case: Northern São Francisco Do Sul Island, Sc, Brazil. Coastal Sediments 2019, 488-501. https://doi.org/10.1142/9789811204487_0044

Davidson, M. A., Lewis, R. P. \& Turner, I. L. (2010). Forecasting seasonal to multi-year shoreline change. Coastal Engineering, 57, 620-629.

Dingemans, M. W., Radder, A. C. \& De Vriend, H. J. (1987). Computation of the driving forces of wave-induced currents. Coastal Engineering, 11, 539-563. https://doi.org/10.1016/0378-3839(87)90026-3

Draper, L. (1967). Wave activity at the sea bed around northwestern Europe. Marine Geology, 5(2), $133-140$. https://doi.org/10.1016/0025-3227(67)90075-8

Drønen, N., Kristensen, S., Taaning, M., Elfrink, B., \& Deigaard, R. (2011). Long term modeling of shoreline response to coastal structures. In: The Proceedings of the Coastal Sediments 2011: In 3 Volumes (pp. 965 -978).

Duarte, J., Taborda, R., Ribeiro, M., Cascalho, J., Silva, A. \& Bosnic, I. (2014). Evidences of sediment bypassing at Nazaré headland revealed by a large scale sand tracer experiment. Proceedings of the 3rd as Jornadas de Engenharia Hidrográica, Lisboa, Portugal, 24-26 June 2014, 289 292.

EMODnet Bathymetry Consortium. (2016). EMODnet Digital Bathymetry (DTM 2016). EMODnet Bathymetry Consortium. https://doi.org/10.12770/c7b53704-999d-4721-b1a3-04ec60c87238

Evans, O. F. (1943). The relation of the action of waves and currents on headlands to the control of shore erosion by groins. Proceedings of the Oklahoma Academy of Sciences, 24, 9-13.

This article is protected by copyright. All rights reserved. 
Fellowes, T. E., Villa-Concejo, A. \& Gallop, S. L. (2019). Morphometric classification of swelldominated embayed beaches. Marine Geology, 411, 78 - 87. https://doi.org/10.1016/j.margeo.2019.02.004

Fitzgerald, D. M., Kraus, N. C. \& Hands, E. B. (2000). Natural Mechanisms of Sediment Bypassing at Tidal Inlets. CHETN-IV-30. U.S. Army Corps of Engineers, Vicksburg, MS. https://apps.dtic.mil/dtic/tr/fulltext/u2/a588774.pdf

Fredsøe, J. (1984). Turbulent boundary layer in wave-current motion. Journal of Hydraulic Engineering, 110(8), $1103-1120$. https://doi.org/10.1061/(ASCE)0733-9429(1984)110:8(1103

Genest, C. \& Favre, A. C. (2007). Everything you always wanted to know about copula modeling but were afraid to ask. Journal of Hydrologic Engineering. 12(4), 347 - 368. https://doi.org/10.1061/(ASCE)1084-0699(2007)12:4(347)

George, D. A., Largier, J. L., Storlazzi, C. D. \& Barnard, P. L. (2015). Classification of rocky headlands in California with relevance to littoral cell boundary delineation. Marine Geology, 369, $137-$ 152.

George, D. A., Largier, J. L., Storlazzi, C. D., Robart, M. J. \& Gaylord, B. (2018). Currents, waves and sediment transport around the headland of Pt. Dume, California. Continental shelf research, $171,63-76$. https://doi.org/10.1016/j.csr.2018.10.011.

George, D. A., Largier, J. L., Pasternack, G. B., Barnard, P. L., Storlazzi, C. D. \& Erikson, L. H. (2019). Modelling sediment bypassing around idealized rocky headlands. Journal of Marine Science and Engineering, 7(40). https://doi.org/10.3390/jmse7020040

Goodwin, I. D., Freeman, R., Blackmore, K. (2013). An insight into headland sand bypassing and wave climate variability from shoreface bathymetric change at Byron Bay, New South Wales, Australia. Marine Geology, 341, $29-45$. https://doi.org/10.1016/j.margeo.2013.05.005

Grunnet, N. M., Walstra, D. J. R. \& Ruessink, B. G. (2004). Process-based modelling of a shoreface nourishment. Coastal Engineering, 51, 581-607. https://doi.org/10.1016/j.coastaleng.2004.07.016

Holt, J. T., James, I. D., \& Jones, E. J. (2001). An s coordinate density evolving model of the northwest European continental shelf: 2. Seasonal currents and tides. Journal of Geophysical Research, 106(C7), 14,035-14,053. https://doi.org/10.1029/2000JC000303

King, E. V., Conley, D. C., Masselink, G., Leonardi, N., McCarroll, R. J., \& Scott, T. (2019). The impact of waves and tides on residual sand transport on a sediment-poor, energetic, and macrotidal continental shelf. Journal of Geophysical Research: Oceans, 124, 4974 - 5002. https://doi.org/10.1029/2018JC014861

King, E. V., Conley, D. C., Masselink, G. \& Leonardi, N. (Under Review). Predicting dominance of sand transport by waves, tides and their interactions on sandy continental shelves. Submitted to: Journal of Geophysical Research: Oceans. Preprint available: https://doi.org/10.1002/essoar.10505948.1

This article is protected by copyright. All rights reserved. 
Klein, A. H. F., Ferreira, Ó., Dias, J. M. A., Tessler, M. G., Silveira, L. F., Benedet, L., de Menezes, J. T. \& de Abreu, J.G.N. (2010). Morphodynamics of structurally controlled headland-bay beaches in southeastern Brazil: A review. Coastal Engineering, 57, 98-111.

Klein, A. H. F., Vieira da Silva, G., Taborda, R., da Silva, A. P. \& Short, A. D. (2020). Headland bypassing and overpassing: form, processes and applications. In Jackson, D. \& Short, A. (Eds.), Sandy Beach Morphodynamics (Vol. 1, pp. 557 - 591). Amsterdam, Netherlands: Elsevier.

Komen, G., Hasselmann S. \& Hasselmann, K. (1984). On the existence of a fully developed wind-sea spectrum. Journal of Physical Oceanography, 14, 1271 - 1285.

Kristensen, S., Dronen, N., Deigaard, R. and Fredsoe, J. (2012). Hybrid morphological modelling of shoreline response to a detached breakwater. Coastal Engineering, 71, 13- 27.

Lesser, G. R., Roelvink, J. A., Van Kester, J. A. T. M., \& Stelling, G. S. (2004). Development and validation of a three-dimensional morphological model. Coastal Engineering, 51(8-9), 883 915.

https://doi.org/10.1016/j.coastaleng.2004.07.014

Luijendijk, A. P., Ranasinghe, R., de Schipper, M. A., Huisman, B. A., Swinkels, C. M., Walstra, D. J. R. \& Stive, M. J. F. (2017). The initial morphological response of the Sand Engine: A processbased modelling study, Coastal Engineering, 119, 1 - 14. https://doi.org/10.1016/j.coastaleng.2016.09.005

Madsen, O., Poon Y. K. \& Graber, H. (1988). Spectral wave attenuation by bottom friction: Theory. Proceedings 21th International Conference Coastal Engineering, ASCE, 492 - 504.

McCarroll, R. J., Brander, R. W., Turner, I. L. \& Van Leeuwen, B. (2016). Shoreface storm morphodynamics and mega-rip evolution at an embayed beach: Bondi Beach, NSW, Australia. Continental Shelf Research, 116, $74-88$. https://doi.org/10.1016/j.csr.2016.01.013

McCarroll, R. J., Masselink, G., Valiente, N. G., Scott, T., King, E. V. \& Conley, D. (2018). Wave and Tidal Controls on Embayment Circulation and Headland Bypassing for an Exposed, Macrotidal Site. Journal of Marine Science and Engineering, 6(3), 94. https://doi.org/10.3390/jmse6030094

McCarroll, R. J., Masselink, G., Wiggins, M., Scott, T., Billson, O., Conley, D. C. \& Valiente, N. G. (2019). High-efficiency gravel longshore sediment transport and headland bypassing over an extreme wave event. Earth Surface Processes and Landforms, 44, 2720-2727. https://doi.org/10.1002/esp.4692

McCarroll, R. J., Masselink, G., Valiente, N. G., King, E. V. Scott, T., Stokes, C. \& Wiggins, M. (2021). An XBeach derived parametric expression for headland bypassing. Coastal Engineering, 103860. https://doi.org/10.1016/j.coastaleng.2021.103860

McConnell, N., King, R., Tonani, M., O'Dea, E., Martin, M., Sykes, P. \& Ryan, A. (2017). North West European Shelf Production Centre NORTHWESTSHELF_ANALYSIS_FORECAST_PHYS_004_001_b. Quality Information Document. Issue 3.5. Copernicus Marine Environment Monitoring Service.

Mouragues, A., Bonneton, P., Castelle, B., Marieu, V., McCarroll, R. J., Rodriguez-Padilla, I., Scott, T. \& Sous, D. (2020). High-energy surf zone currents and headland rips at a geologically constrained mesotidal beach. Journal of Geophysical Research: Oceans, 125, e2020JC016259. https://doi.org/10.1029/2020JC016259

This article is protected by copyright. All rights reserved. 
O'Dea, E. J., Arnold, A. K., Edwards, K. P., Furner, R., Hyder, P., Martin, M. J., Siddorn, J. R., Storkey, D., While, J., Holt, J. T., \& Liu, H. (2012). An operational ocean forecast system incorporating NEMO and SST data assimilation for the tidally driven European North-West shelf. Journal of Operational Oceanography, 5(1), $3-17$.

https://doi.org/10.1080/1755876X.2012.11020128

Oyedotun, T. D. T. (2020). Compositional and multivariate statistical analyses for grain-size characterisation of intertidal sedimentary facies in an estuarine environment. Geology, Ecology and Landscapes, 4 (4). https://doi.org/10.1080/24749508.2020.1814186

Pingree, R. D., \& Griffiths, D. K. (1979). Sand transport paths around the British Isles resulting from M2 and M4 tidal interactions. Journal of the Marine Biological Association of the United Kingdom, 59(2), 497- 513. https://doi.org/10.1017/S0025315400042806

Prodger, S., Russell, P., Davidson, M., Miles, J. \& Scott, T. (2016). Understanding and predicting the temporal variability of sediment grain size characteristics on high-energy beaches. Marine Geology, 376, $109-117$.

Prodger, S., Russell, P., \& Davidson, M. (2017). Grain-size distributions on high-energy sandy beaches and their relation to wave dissipation. Sedimentology, 64(5), $1289-1302$.

https://doi.org/10.1111/sed.12353

Ribeiro, M. S. A. (2017). Headland sediment bypassing processes (Doctoral dissertation). University of Lisbon. 229 p.

https://pdfs.semanticscholar.org/e6be/c734b7b57592213848201567a80e1157d2b7.pdf

Robinet, A., Idier, D., Castelle, B., \& Marieu, V. (2018). A reduced-complexity shoreline change model combining longshore and cross-shore processes: the LX-Shore model. Environmental modelling \& software, 109, 1- 16.

Robinet, A., Castelle, B., Idier, D., Harley, M. D., \& Splinter, K. D. (2020). Controls of local geology and cross-shore/longshore processes on embayed beach shoreline variability. Marine Geology, 106118.

Roelvink, D., Huisman, B., Elghandour, A., Ghonim, M., \& Reyns, J. (2020). Efficient modeling of complex sandy coastal evolution at monthly to century time scales. Frontiers in Marine Science, 7, 535.

Saha, S., Moorthi, S., Wu, X., Wang, J., Nadiga, S., Tripp, P., Behringer, D., Hou, Y. T., Chuang, H. Y., Iredell, M., Ek, M., Meng, J., Yang, R., Mendez, M. P., van den Dool, H., Zhang, Q., Wang, W., Chen, M., \& Becker, E. (2014). The NCEP Climate Forecast System version 2. Journal of Climate, 27(6), $2185-2208$.

https://doi.org/10.1175/JCLI-D-12-00823.1

Saulter, A. (2017). North West European Shelf Production Centre: NORTHWESTSHELF_ANALYSIS_FORECAST_WAV_004_012. Quality Information Document. Issue 1.0. Copernicus Marine Environment Monitoring Service.

Scott, T., Austin, M., Masselink, G. \& Russell, P. (2016a). Dynamics of rip currents associated with groynes - Field measurements, modelling and implications for beach safety. Coastal Engineering, 107, $53-69$.

Scott, T., Masselink, G., O'Hare, T., Saulter, A., Poate, T., Russell, P., Davidson, M. \& Conley, D. (2016b). The extreme 2013/2014 winter storms: Beach recovery along the southwest coast

This article is protected by copyright. All rights reserved. 
of England. Marine Geology, 382, 224 - 241.

https://doi.org/10.1016/j.margeo.2016.10.011.

Short, A. D. (1985). Rip-current type, spacing and persistence, Narrabeen Beach, Australia. Marine Geology, 65(1-2), $47-71$. https://doi.org/10.1016/0025-3227(85)90046-5

Short, A. D. \& Masselink, G. (1999). Structurally Controlled Beaches. In Handbook of Beach and Shoreface Morphodynamics; Short, A.D., Ed.; JohnWiley and Sons Ltd.: Chichester, UK, 1999; pp. 230-250.

Soulsby, R. L., Hamm, L., Klopman, G., Myrhaug, D., Simons, R. R., \& Thomas, G. P. (1993). Wavecurrent interaction within and outside the bottom boundary layer. Coastal Engineering, 21(1-3), $41-69$. https://doi.org/10.1016/0378-3839(93)90045-a

Thom B. G., Eliot, I., Eliot, M., Harvey, N., Rissik, D., Sharples, C., Short, A. D. \& Woodroffe, C. D. (2018). National sediment compartment framework for Australian coastal management. Ocean and Coastal Management, 154, $103-120$.

Toimil, A., Losada, I. J., Camus, P., \& Diaz-Simal, P. (2017). Managing coastal erosion under climate change at the regional scale. Coastal Engineering, 128, 106- 122.

Turner, J. F., Iliffe, J. C., Ziebart, M. K., Wilson, C., \& Horsburgh, K. J. (2010). Interpolation of tidal levels in the coastal zone for the creation of a hydrographic datum. Journal of Atmospheric and Ocean Technology, 27(3), $605-613$. https://doi.org/10.1175/2009JTECH0645.1

Uncles, R. J. (2010). Physical properties and processes in the Bristol Channel and Severn Estuary. Marine Pollution Bulletin, 61(1-3), 5- 20. https://doi.org/10.1016/j.marpolbul.2009.12.010

Valiente, N. G., Masselink., G., Scott, T., Conley, D. C. \& McCarroll, R. J. (2019a). Role of waves and tides on depth of closure and potential for headland bypassing. Marine Geology, 407, $60-$ 75.

https://doi.org/10.1016/j.margeo.2018.10.009

Valiente, N. G., McCarroll, R. J., Masselink., G., Scott, T. \& Wiggins, M. (2019b). Multi-annual embayment sediment dynamics involving headland bypassing and sediment exchange across the depth of closure. Geomorphology, 343, $48-64$. https://doi.org/10.1016/j.geomorph.2019.06.020

Valiente, N. G., Masselink., G., McCarroll, R. J., Scott, T., Conley, D. C. \& King, E. V. (2020). Nearshore sediment pathways and potential sediment budgets in embayed settings over a multi-annual timescale. Marine Geology, 427, 106270. https://doi.org/10.1016/j.margeo.2020.106270

van Rijn, L. C., Walstra, D. J. R. \& van Ormondt, M. (2004). Description of TRANSPOR2004 and implementation in Delft3D-ONLINE, Final Report. Report Z3748.10. Delft, The Netherlands: WL Delft Hydraulics.

van Rijn, L. C. (2014). A simple general expression for longshore transport of sand, gravel and shingle. Coastal Engineering, 90, 23 - 39.

van Rijn, L. C. (2007a). Unified view of sediment transport by currents and waves. I: Initiation of motion, bed roughness, and bed-load transport. Journal of Hydraulic Engineering, 133(6),

This article is protected by copyright. All rights reserved. 
$649-667$.

https://doi.org/10.1061/(ASCE)0733-9429(2007)133:6(649

van Rijn, L. C. (2007b). Unified view of sediment transport by currents and waves. II: Suspended transport. Journal of Hydraulic Engineering, 133(6), 668 - 689.

https://doi.org/10.1061/(ASCE)0733-9429(2007)133:6(668

Vieira da Silva, G., Toldo, E. E., Klein, A. H. D. F., Short, A. D. \& Woodroffe, C. D. (2016). Headland sand bypassing-Quantification of net sediment transport in embayed beaches, Santa Catarina Island North Shore, Southern Brazil. Marine Geology, 379, 13 - 27.

Vieira da Silva, G., Toldo, E. E., Klein, A. H. D. F. \& Short, A. D. (2018). The influence of wave-, windand tide-forced currents on headland sand bypassing-Study case: Santa Catarina Island north shore, Brazil. Geomorphology, 312, 1 - 11.

Vitousek, S., Barnard, P. L., Limber, P., Erikson, L., \& Cole, B. (2017). A model integrating longshore and cross-shore processes for predicting long-term shoreline response to climate change. Journal of Geophysical Research: Earth Surface, 122(4), 782 - 806.

Wiggins, M., Scott, T., Masselink, G., Russell, P. \& McCarroll, R. J. (2019). Coastal embayment rotation: Response to extreme events and climate control, using full embayment surveys. Geomorphology, 327, 385-403. https://doi.org/10.1016/j.geomorph.2018.11.014

Willmott, C. J., Robeson, S. M., \& Matsuura, K. (2012). A refined index of model performance. International Journal of Climatology, 32(13), 2088-2094. https://doi.org/10.1002/joc.2419

Wishaw, D., Leon, J., Fairweather, H., \& Crampton, A. (2021). Influence of wave direction sequencing and regional climate drivers on sediment headland bypassing. Geomorphology, 383, 107708. https://doi.org/10.1016/j.geomorph.2021.107708

Young, I. R., Zieger, S., \& Babanin, A. V. (2011). Global trends in wind speed and wave height. Science, 332(6028), $451-455$. https://doi.org/10.1126/science.1197219

This article is protected by copyright. All rights reserved. 


\section{Appendices}

\section{Appendix A: Model parameters}

Table A1: Hydrodynamic physical parameters.

\begin{tabular}{l|l|l} 
Parameter & Value & Units \\
\hline Horizontal eddy viscosity & 1 & $\mathrm{~m}^{2} \mathrm{~s}^{-1}$ \\
Horizontal eddy diffusivity & 10 & $\mathrm{~m}^{2} \mathrm{~s}^{-1}$ \\
Gravitational acceleration & 9.81 & $\mathrm{~m} \mathrm{~s}^{-2}$ \\
Water density & 1025 & $\mathrm{~kg} \mathrm{~m}^{-3}$ \\
Water temperature & 15 & ${ }^{\circ} \mathrm{C}$ \\
Salinity & 35 & PPT \\
Wave related bottom stress formulation & Fredsøe $(1984)$ & - \\
Wind drag coefficients & $2 \mathrm{e}^{-3}, 0,7.23 \mathrm{e}^{-3}, 100$, &,$- \mathrm{m} \mathrm{s}^{-1}$ \\
& $7.23 \mathrm{e}^{-3}, 100$ & \\
Air density & 1 & $\mathrm{~kg} \mathrm{~m}^{-3}$ \\
Spiral motion & Included in & - \\
Bottom friction formulation & hydrodynamics & \\
Bottom friction coefficient $\mathrm{u}, \mathrm{v}$ & Manning & - \\
Drying/ flooding threshold depth & $2.75 \mathrm{e}^{-2}, 2.75 \mathrm{e}^{-2}$ & $\mathrm{~s} \mathrm{~m}^{-1 / 3}$ \\
\end{tabular}

Table A2: Hydrodynamic numerical parameters.

\begin{tabular}{l|l|l} 
Parameter & Value & Units \\
\hline Computational time step & 0.2 & mins \\
Iterations in continuity equation & 2 & - \\
Number of sigma layers & 10 & - \\
Sigma layer thickness (surface - bed) & $20,20,15,12,10,8,6,4,3,2$ & $\%$ depth \\
If depth < threshold, set whole cell to dry & YES & - \\
Depth determination at water level points when & MEAN & - \\
all vertices wet & & \\
Depth determination at velocity points when all & MEAN & \\
vertices wet & 0.05 & m \\
Drying/ flooding threshold & -999 & m \\
Marginal depth in shallow areas & 1440 & mins \\
Smoothing time at start of simulation &
\end{tabular}

This article is protected by copyright. All rights reserved. 
Numerical method for advective terms

Numerical method for momentum terms

Output storage time interval

Communication time interval with WAVE

Cyclic-method
Cyclic
60
60

$\mid \begin{aligned} & - \\ & - \\ & \text { mins } \\ & \text { mins }\end{aligned}$

Table A3: Wave physical processes and parameters.

\begin{tabular}{l|l|l} 
Process/ Parameter & Value & Units \\
\hline Water level correction & 0 & $\mathrm{~m}$ \\
Water levels & From FLOW & - \\
Currents & From FLOW & - \\
Gravitational acceleration & 9.81 & $\mathrm{~m} \mathrm{~s}^{-2}$ \\
Water density & 1025 & $\mathrm{~kg} \mathrm{~m}^{-3}$ \\
North direction & $90^{\circ}$ & Cartesian \\
Minimum depth & 0.05 & $\mathrm{~m}$ \\
Physics & $3^{\text {rd Generation }}$ & - \\
Wave breaking & true & - \\
Alpha coefficient for wave breaking & 1 & - \\
Gamma coefficient for wave breaking & 0.73 & - \\
Non-linear triad interactions & true & - \\
Triad alpha proportionality coefficient & 0.1 & - \\
Triad beta max frequency ratio & 2.2 & - \\
Bed friction formulation & Madsen et al. (1988) & - \\
Bed friction coefficient & 0.05 & $\mathrm{~m}^{2} \mathrm{~s}^{-3}$ \\
Diffraction & false & - \\
Wind growth & false \\
Whitecapping formulation & Komen et al. (1984) \\
Quadruplets & false & - \\
Refraction & true \\
Frequency shifting & true \\
Method of wave force computation & dissipation 3d \\
\end{tabular}


Table A4: Numerical parameters in the CRM.

\begin{tabular}{|c|c|c|}
\hline Process/ Parameter & Value & Units \\
\hline Computational mode & Non-stationary & - \\
\hline Computational time step & 10 & mins \\
\hline Discretisation in directional space & 0.5 & - \\
\hline Discretisation in frequency space & 0.5 & - \\
\hline $\begin{array}{l}\text { Relative change of wave height or mean wave } \\
\text { period with respect to local value }\end{array}$ & 0.05 & - \\
\hline $\begin{array}{l}\text { Relative change of wave height with respect to } \\
\text { model-wide average wave height }\end{array}$ & 0.05 & - \\
\hline $\begin{array}{l}\text { Relative change of mean wave period with } \\
\text { respect to model-wide average mean wave } \\
\text { period }\end{array}$ & 0.05 & - \\
\hline $\begin{array}{l}\text { Percentage of points for accuracy criteria } \\
\text { satisfaction }\end{array}$ & 98 & $\%$ \\
\hline maximum number of iterations & 15 & - \\
\hline Directional resolution & 10 & $\circ$ \\
\hline Frequency min, max & $0.05,1$ & $\mathrm{~Hz}$ \\
\hline $\mathrm{N}$ frequency bins & 24 & - \\
\hline
\end{tabular}

\section{Appendix B: Skill metrics}

Skill was assessed using the following metrics: $R^{2}, B I A S$, mean absolute error MAE, Willmott Index of Agreement WIA and Brier Skill Score BSS. This appendix covers the calculation of the BIAS, MAE, WIA, and BSS metrics. BIAS was determined as:

$$
B I A S=\frac{\sum_{i=1}^{n}\left(P_{i}-O_{i}\right)}{n},
$$

Where $P_{i}$ is the $i^{\text {th }}$ model prediction and $O_{i}$ is the $i^{\text {th }}$ observed value, $n$ is the total number of data points for comparison. MAE was determined as:

$$
M A E=\frac{\sum_{i=1}^{n}\left(\left|P_{i}-O_{i}\right|\right)}{n},
$$

This article is protected by copyright. All rights reserved. 
WIA (Willmott et al., 2012) is given by:

$$
d_{r}=\left\{\begin{array}{c}
1-\frac{\sum_{i=1}^{n}\left|P_{i}-O_{i}\right|}{2 \sum_{i=1}^{n}\left|O_{i}-\bar{O}\right|}, \text { when } \\
\sum_{i=1}^{n}\left|P_{i}-O_{i}\right| \leq 2 \sum_{i=1}^{n}\left|O_{i}-\bar{O}\right| \\
2 \sum_{i=1}^{n}\left|O_{i}-\bar{O}\right| \\
\sum_{i=1}^{n}\left|P_{i}-O_{i}\right| \\
\sum_{i=1}^{n}\left|P_{i}-O_{i}\right|>2 \sum_{i=1}^{n}\left|O_{i}-\bar{O}\right|
\end{array},\right.
$$

Where $\bar{P}$ and $\bar{O}$ are the mean prediction and observation, respectively. WIA varies from -1 to 1 , indicating the magnitude of the summed predictive error relative to the summed observed deviations about the mean observation. A value $>0$ indicates the summed error magnitudes is less than the summed magnitude of the observed variation about the mean (by half for WIA $=0.5$ ).

BSS is determined following Davidson et al., (2010) as:

$$
B S S=1-\frac{\left\langle\left(\left|P_{i}-O_{i}\right|-\epsilon\right)^{2}\right\rangle}{\left\langle\left(\left|F_{i}-O_{i}\right|\right)^{2}\right\rangle}
$$

Where $F_{i}$ represents the $i^{\text {th }}$ value interpolated from a linear fit to the observation data and $\varepsilon$ is the observation error. Observation errors used were $0.1 \mathrm{~m}$ for $H_{s}, 1 \mathrm{~s}$ for $T_{p}, 5^{\circ}$ for direction and $0.02 \mathrm{~ms}^{-1}$ for currents, in accordance with McCarroll et al., (2018). Angle brackets represent the time mean.

This article is protected by copyright. All rights reserved. 